\title{
Modeling and interpretation of stable carbon isotope ratios of ethane in global chemical transport models
}

\author{
Olaf Stein ${ }^{1,2}$ and Jochen Rudolph ${ }^{1,3}$ \\ Received 22 September 2006; revised 24 April 2007; accepted 9 May 2007; published 25 July 2007.
}

[1] Model calculations with two global 3D-CTMs (GISS and MOZART-2) in which we introduced ethane stable carbon isotopic ratios were performed. In both models, emission inventories based on the EDGAR database are used for VOC emissions. We considered source specific isotope fractionations and included global emissions from C3 and $\mathrm{C} 4$ plants which differ significantly in isotope ratio. Comparison of the model results with observation strongly indicates that the EDGAR emission inventory underestimates global ethane emissions by a factor of approximately 1.5 . On the basis of the latitudedependent differences between model predictions and the atmospheric observations of ethane reported by Rudolph (1995), estimates of magnitude and latitude range of sources missing in current emission inventories are made. However, the concentration data alone provide only limited constraints on the geographical distribution and only indirect information about the type of the missing sources. Isotope ratio studies can be very valuable to obtain additional insight. To study the dependence between the geographical distribution of the emissions and atmospheric ethane concentrations and isotope ratios, MOZART-2 model calculations were made where all emissions are concentrated in latitude bands as well as in specified regions. Two regimes can be distinguished on a global scale: In the source latitude band, dilution with background air explains most of the calculated concentration variation, while at latitudes farther away from the sources, chemical loss is the dominating process.

Citation: Stein, O., and J. Rudolph (2007), Modeling and interpretation of stable carbon isotope ratios of ethane in global chemical transport models, J. Geophys. Res., 112, D14308, doi:10.1029/2006JD008062.

\section{Introduction}

[2] During the last years measurements of stable carbon isotope ratios have been developed into a promising tool for studying the atmospheric chemistry of volatile organic compounds (VOC). Following the development of experimental methods for precise and accurate measurements of the stable carbon isotope ratio of VOC [Rudolph et al., 1997] a number of studies were conducted, which demonstrated possible uses of carbon isotope ratio measurements for the investigation of origin and photochemical processing of VOC [Tsunogai et al., 1999; Saito et al., 2002; Thompson et al., 2003]. Nevertheless, the theoretical framework for the interpretation of stable isotope ratios of atmospheric VOC is still very limited. Model calculations have the potential to allow detailed insight into the complex dependence between emissions, atmospheric transport processes, chemical reactions and the stable carbon isotope ratios of VOC. To our knowledge only one 3D model study of the stable carbon

\footnotetext{
${ }^{1}$ Institut für Chemie und Dynamik der Geosphäre-2: Troposphäre, Forschungszentrum Jülich, Jülich, Germany.

${ }^{2}$ Also at Max Planck Institute for Meteorology, Hamburg, Germany.

${ }^{3}$ Also at Centre for Atmospheric Chemistry, Chemistry Department, York University, Toronto, Ontario, Canada.

Copyright 2007 by the American Geophysical Union. 0148-0227/07/2006JD008062\$09.00
}

isotope ratios of VOC has been published to date [Thompson et al., 2003]. This study was based on a uniform stable carbon isotope ratio for all sources and presented no information with respect to the sensitivity of atmospheric stable carbon isotope ratios on the emission rates and stable carbon isotope ratio of the VOC sources.

[3] In this paper we present the results of global 3-D model calculations of the stable carbon isotope ratio and concentration of atmospheric ethane. Ethane is chosen as example for a number of reasons. First, there are a substantial number of measurements of the atmospheric concentration of ethane, as well as a small number of measurements of its stable carbon isotope ratio. Second, the atmospheric residence time of ethane is sufficiently long to justify meaningful comparison between spot measurements and results of global model calculations. Finally, all major sources of ethane are also significant sources for other important atmospheric trace gases, which allows using ethane as a tracer for important trace gas sources such as natural gas losses or biomass burning. The results will be used to determine the dependence of atmospheric ethane concentrations and stable isotope ratios on key input parameters. Furthermore, different models and transport fields will be compared to determine the sensitivity of predicted ethane concentrations and isotope ratios on model specific parameters. 
[4] Although the main emphasis of this paper is on the modeling of isotope ratios and their possible use for model testing and validation, we will also have a more detailed look at the distribution and strength of ethane emissions since there is strong evidence that present emission inventories result in underestimates of atmospheric ethane mixing ratios. Gautrois et al. [2003] reported that identified emissions are insufficient to explain the magnitude of mixing ratios observed at Alert (Canadian Arctic). Rudolph [1995] estimated that the global source ethane strength required to balance atmospheric removal is $15.5 \mathrm{Tg} / \mathrm{yr}$, which is about $50 \%$ higher than present emission estimates.

\section{Theory}

[5] In principle isotope ratios can be modeled by including the isotopically labeled compounds as separate chemical species and treating them separately, according to their specific properties. However, for practical applications there are some specific considerations, which can be useful to reduce computational effort or simplify interpretation of modeling results and atmospheric observations. The chemical and physical properties of isotopically labeled and unlabeled compounds, the isotopologues, are very similar although not completely identical. Therefore it is customary to measure and present isotope information in the form of ratios. For example instead of concentrations of the individual isotopologues usually the ratio of the concentrations is given. Furthermore, since changes in isotope ratios are generally very small, they usually are presented as the relative difference between the observed stable isotope ratio and the isotope ratio of a reference standard. For stable carbon isotope ratios the internationally accepted reference point is Vienna Peedee Belemnite (V-PDB). Thus stable carbon isotope ratios are typically expressed in delta notation as per mil (\%) values relative to V-PDB.

$$
\delta^{13} C=\frac{\left(\frac{\left[{ }^{13} C\right]}{\left[{ }^{12} C\right]}\right)_{\text {sample }}-\left(\frac{\left[{ }^{13} C\right]}{\left[{ }^{12} C\right]}\right)_{\text {reference }}}{\left(\frac{\left[{ }^{13} C\right]}{\left[{ }^{12} C\right]}\right)_{\text {reference }}} \cdot 1000 \%
$$

[6] Similarly, reaction rate constants for isotope labeled compounds are expressed as ratio of the rate constants of the isotopologues, the kinetic isotope effect (KIE). For VOC with natural carbon isotope abundances the carbon KIE is defined as the ratio of the rate constants of the only ${ }^{12} \mathrm{C}$ containing isotopologue $\left(\mathrm{k}_{12}\right)$ over the rate constant of the isotopologue containing one ${ }^{13} \mathrm{C}$ atom $\left(\mathrm{k}_{13}\right)$ :

$$
K I E=\frac{k_{12}}{k_{13}}
$$

[7] In the case of carbon isotopes only $1.1 \%$ of the total carbon is ${ }^{13} \mathrm{C}$ and consequently the probability that small molecules contain more than one ${ }^{13} \mathrm{C}$ atom is very small and therefore can be neglected. Since most KIEs have values very close to one, they are, for the sake of convenience and similar to the $\delta$-notation for isotope ratios, given as $\varepsilon$ values in per mil:

$$
\varepsilon=(K I E-1) \cdot 1000 \%=\left(\frac{k_{12}}{k_{13}}-1\right) \cdot 1000 \%
$$

[8] Because of the low fraction of ${ }^{13} \mathrm{C}$ in carbon, the small carbon isotope effects, and the very small changes in carbon isotope ratios in the environment, the feedback of changes in stable carbon isotope ratios on the chemistry of the atmosphere will be extremely small. For example change of the stable carbon isotope ratio of ethane in the range of $50 \%$, which is at the upper end of its variation in the atmosphere, will change the reactivity of ethane by less than $10^{-3 \%}$. The importance of carbon isotope ratios lies in their possible use as tracers to study atmospheric processes and not in their impact on the chemistry of the atmosphere.

[9] Carbon isotope effects are often so small, that it is possible to use linear approximations for the relation between isotope ratios and atmospheric processes without introducing significant bias. Rudolph and Czuba [2000] have demonstrated that for a hydrocarbon $\mathrm{HC}$ which is only removed by reaction with $\mathrm{OH}$ radicals a simple relation between the extent of chemical processing, the stable isotope ratio at the time of emission $\left(\delta_{H C}^{0}\right)$ and the atmospheric stable carbon isotope ratio $\left(\delta_{H C}\right)$ exists:

$$
\delta_{H C}=\delta_{H C}^{0}+\varepsilon_{O H} \cdot k_{O H} \cdot[O H]_{a v} \cdot t_{a v}
$$

[10] Here $\varepsilon_{\mathrm{OH}}$ is the KIE and $k_{O H}$ the rate constant for the reaction of the hydrocarbon with the $\mathrm{OH}$ radical, $\mathrm{t}_{\mathrm{av}}$ the average age of the studied hydrocarbons, and $[\mathrm{OH}]_{\mathrm{av}}$ the average $\mathrm{OH}$ radical concentration. For the product of $\mathrm{t}_{\mathrm{av}}$ and $[\mathrm{OH}]_{\mathrm{av}}$ often the term photochemical age is used, in order to distinguish it from the average physical age, $t_{a v}$ [Parrish et al., 1992]. However, the term photochemical age has to be used with some care since it does not have the dimension of a true age. Furthermore, it has to be considered that different compounds with different source distributions or atmospheric residence times can differ in their photochemical ages in an air mass. In the following the term photochemical age always refers to the studied compound, ethane.

[11] Equation (4) is based on the assumption that the isotopic composition of all sources can be approximated by one average stable isotope ratio. For a more general case we have to consider the possibility that a variety of sources or source types with different isotopic signatures exists and equation (4) has to be modified:

$$
\begin{aligned}
\delta_{H C}= & \frac{\sum_{i} c_{i} \cdot\left(\delta_{H C}^{i}+\varepsilon_{O H} \cdot k_{O H} \cdot[O H]_{a v}^{i} \cdot t_{a v}^{i}\right)}{\sum_{i} c_{i}} \\
= & \frac{\sum_{i} c_{i} \cdot \delta_{H C}^{i}}{\sum_{i} c_{i}}+\frac{\varepsilon_{O H} \cdot k_{O H} \cdot \sum_{i} c_{i} \cdot[O H]_{a v}^{i} \cdot t_{a v}^{i}}{\sum_{i} c_{i}}
\end{aligned}
$$


Table 1. GISS Ethane Surface Emissions (GEIA/EDGAR V2.0)

\begin{tabular}{lc}
\hline \multicolumn{1}{c}{ Source } & $\begin{array}{c}\text { Total Annual } \\
\text { Global Emissions, } \\
\text { Tg/yr Ethane }\end{array}$ \\
\hline Industry/fossil fuel & 3.91 \\
Biofuel combustion & 1.84 \\
Large-scale biomass burning & 1.17 \\
Waste treatment & 1.28 \\
Total & 8.20 \\
\hline
\end{tabular}

[12] Here $c_{i}$ are the contributions from different sources or source types to the total concentration of the hydrocarbon, $c_{H C}=\sum_{i} c_{i}$, and $[O H]_{a v}^{i} \cdot t_{a v}^{i}$ are the corresponding average photochemical ages for these contributions. Both equations (4) and (5) contain two additive terms, which separately reflect the influence of source composition and atmospheric reactions:

$$
\delta_{S}=\frac{\sum_{i} c_{i} \cdot \delta_{H C}^{i}}{\sum_{i} c_{i}}
$$

and

$$
\delta_{a}=\frac{\varepsilon_{O H} \cdot k_{O H} \cdot \sum_{i} c_{i} \cdot[O H]_{a v}^{i} \cdot t_{a v}^{i}}{\sum_{i} c_{i}}
$$

[13] Both terms include the hydrocarbon concentrations, which are connected to atmospheric transport and chemistry in a complex manner. Nevertheless, equations (5)-(7) can be very valuable to place additional constraints on the processes determining the atmospheric distribution and chemistry of hydrocarbons.

[14] In the case of VOC with a small feedback on the chemistry of the atmosphere it is possible to use linear approximations to describe the dependence between a changed emission rate of source $\mathrm{i}\left(\Delta \mathrm{E}_{\mathrm{i}}\right)$ and the resulting change in concentrations $\left(\Delta \mathrm{c}_{\mathrm{i}}\right)$ :

$$
\Delta c_{i}=\frac{d c_{i}}{d E_{i}} \cdot \Delta E_{i}
$$

[15] If the overall feedback of source $\mathrm{i}$ on the loss mechanism of the hydrocarbon is negligible $\mathrm{dc}_{\mathrm{i}} / \mathrm{dE}_{\mathrm{i}}$ can be replaced by $c_{i} / E_{i}$, the ratio of the contribution $c_{i}$ of source $i$ over the emission rate $\mathrm{E}_{\mathrm{i}}$ of this source:

$$
\Delta c_{i}=\frac{c_{i}}{E_{i}} \cdot \Delta E_{i}
$$

[16] Then the new concentration $\left(c_{E+\Delta E_{i}}\right)$ after a change in emission rates of $\Delta \mathrm{E}_{\mathrm{i}}$ can be approximated by:

$$
c_{E+\Delta E_{i}}=c_{E}+\frac{c_{i}}{E_{i}} \cdot \Delta E_{i}
$$

where $c_{E}$ represents the concentration prior to the change in emission rate.

\section{Model Description}

\subsection{GISS}

[17] The GISS CTM (Goddard Institute for Space Sciences Chemical Transport Model) calculations of isotope ratios were similar to the Isotope Inclusive CTM $\left(\mathrm{I}^{2} \mathrm{CTM}\right)$, which is described in detail by Thompson et al. [2003] and therefore only a brief description is given here. The GISS CTM model is adopted from Prather et al. [1987] and solves the continuity equation for a set of chemically reactive tracers over a global three-dimensional grid, which covers for this study $4^{\circ} \times 5^{\circ}$ (lat./lon.). Nine vertical sigmalayers are reaching from the surface up to $40 \mathrm{hPa}$. The model uses a split-operator method to compute the effects of advection, dry and wet convection, large-scale diffusion, sources, and chemistry. Details of the convection treatment are given by Kraus et al. [1996]. Treatment of dynamic processes (advection, wet and dry deposition) is based on the precalculated values for each 8 hour time step using meteorological input fields from the GISS GCM II [Hansen et al., 1983]. This data set contains 8-hour averages of mass flux, pressure fields, and convection frequencies, as well as 5-day averages of temperature and detailed convection statistics for one climatological year.

[18] The model chemistry was kept as simple as possible: It allows one VOC tracer to be emitted and transported during a model run. The chemistry includes only removal of the tracer species via reaction with $\mathrm{OH}$ radicals. $\mathrm{OH}$ concentrations are prescribed by a time-dependent threedimensional field [Spivakovsky et al., 2000]. Products, secondary reactions, and feedback mechanisms were ignored, simplifying the model and thus substantially reducing computational efforts. The chemistry is calculated every hour. Ethane emissions are from the GEIA/EDGAR V2.0 database [Olivier et al., 1996], giving typical emissions for the year 1990 on a global $1^{\circ} \times 1^{\circ}$ (lat./lon.) grid. It accounts for 14 different anthropogenic and biogenic source types. Table 1 gives the emission rates used in the GISS calculations divided into the four basic categories. Emission rates were held constant throughout the year.

\subsection{MOZART-2}

[19] MOZART-2 (Model for Ozone and Related TracersVersion 2) is a global three-dimensional chemical transport model with detailed description of tropospheric ozone$\mathrm{NO}_{\mathrm{x}}$-hydrocarbon chemistry and transport as well as of tracer advection, convection and diffusion processes, dry and wet deposition. The model is described in detail by Horowitz et al. [2003]. The horizontal and vertical resolution is highly flexible. We are using horizontal grid T42, which corresponds to approximately $2.8^{\circ}$ latitude $\times 2.8^{\circ}$ longitude horizontal resolution. In the vertical 31 sigma-layers are covering the atmosphere from the surface up to $10 \mathrm{hPa}$. Tracer advection is performed using a flux-form semiLagrangian scheme [Lin and Rood, 1996] with a pressure fixer. Stratospheric concentrations of long-living species are constrained by relaxation toward climatological values.

[20] In this study MOZART-2 is driven with meteorological inputs from ECMWF analyses for the years 1994 and 
Table 2. MOZART-2 Ethane Surface Emissions and Source Specific Stable Carbon Isotope Fractionation Used in This Study

\begin{tabular}{lcc}
\multicolumn{1}{c}{ Source } & $\begin{array}{c}\text { Total Annual } \\
\text { Global Emissions, } \\
\text { Tg/yr Ethane }\end{array}$ & $\begin{array}{c}\delta_{\mathrm{S}} \text { Used in } \\
\text { This Study, } \\
\% \text { o }\end{array}$ \\
\hline Gas production and transmission & 1.83 & -32 \\
Oil production and transmission & 1.36 & $-26^{\mathrm{a}}$ \\
Other fossil fuel and industrial & 1.46 & $-26^{\mathrm{a}}$ \\
$\quad$ biofuel combustion & 2.79 & $-27^{\mathrm{a}}$ \\
Biomass burning from C3 plants & 1.25 & $-13^{\mathrm{a}}$ \\
Biomass burning from C4 plants & 0.80 & -27 \\
Biogenic/vegetation & 0.08 & -22 \\
Oceans & 9.57 & \\
Total & &
\end{tabular}

${ }^{\mathrm{a}} \delta_{\mathrm{S}}$ values following Boutton [1991].

${ }^{\mathrm{b}}$ Including agricultural waste burning and fuelwood burning

1995, which are available in horizontal resolution T106 and are interpolated to the T42 grid. The vertical resolution is the same as in the CTM. The meteorological input data, which is provided to MOZART-2 every 6 hours consists of horizontal winds, temperature, humidity, surface pressure, and surface fluxes of heat and momentum. The standard chemical scheme used in MOZART-2 includes 63 chemical species and 167 reactions (gas phase, photolysis, and heterogeneous reactions). It includes oxidation schemes for $\mathrm{CO}$ and the nonmethane hydrocarbons: ethane, propane, ethene, propene, isoprene, $\alpha$-pinene, and n-butane. The chemical system is solved numerically using a fully implicit Euler backward method with Newton-Raphson iteration using a time step of $20 \mathrm{~min}$.

[21] We are using global emissions as described by Horowitz et al. [2003]: annual emissions (Table 2) are intended to be representative for the early 1990s. Anthropogenic emissions from fossil fuel combustion, fuel wood burning, and agricultural waste burning are based on the EDGAR V2.0 database with the seasonality from Müller [1992]. For some model runs the ethane emission rate was kept constant at the average annual emission rate. Emissions from biomass burning are based on Hao and Liu [1994] in the tropics, and Müller [1992] in the extratropics using emission ratios for chemical species from Andreae and Merlet [2001]. Biogenic emissions of hydrocarbons from vegetation are taken from GEIA [Guenther et al., 1995] and Müller [1992] with reduced emissions for isoprene in the tropics. For details on the used soil emissions, aircraft emissions, and emissions from the ocean as well as on $\mathrm{NO}_{\mathrm{x}}$ emissions from lightning see Horowitz et al. [2003].

\subsection{Modeling Stable Carbon Isotopes}

[22] For the purpose of this study we introduced ${ }^{13}$ ethane as an additional tracer in the CTM for all model simulations described in the following. Emission behavior is the same as for ${ }^{12}$ ethane for each run. This isotopologue behaves identically to the normal ${ }^{12}$ ethane, except for a slightly different rate constant for the reaction with the $\mathrm{OH}$ radical $\left(\mathrm{k}_{\mathrm{OH}}\right)$ due to the kinetic isotope effect (KIE). These rate constants are expressed as follows:

GISS:

$$
{ }^{12} C: k_{O H}=1.520 \cdot 10^{-17} \exp \left(-\frac{498}{T}\right) T^{2}
$$

$$
{ }^{13} C: k_{O H}=1.511 \cdot 10^{-17} \exp \left(-\frac{498}{T}\right) T^{2}
$$

MOZART-2:

$$
\begin{gathered}
{ }^{12} C: k_{O H}=8.70 \cdot 10^{-12} \exp \left(-\frac{1070}{T}\right) \\
{ }^{13} C: k_{O H}=8.65 \cdot 10^{-12} \exp \left(-\frac{1070}{T}\right)
\end{gathered}
$$

[23] This corresponds to an $\varepsilon_{\mathrm{OH}}$ of $5.92 \%$ for the GISS model and to an $\varepsilon_{\mathrm{OH}}$ of $5.75 \%$ o for MOZART-2. The small difference in the KIEs is due to rounding of the rate constants. These values are at the lower end of a very recently published range of measurements [Anderson et al., $2004]$ which gave an $\varepsilon_{\mathrm{OH}}=8.59 \pm 2 \%$ for ethane. On the basis of equations (4) and (5) the modeled isotope ratios can be scaled to different $\varepsilon_{\mathrm{OH}}$ values without repeating the model calculations. To be consistent with the most recent KIE for reaction of $\mathrm{OH}$ with ethane the results presented in the following are scaled according to equation (5) to an $\varepsilon_{\mathrm{OH}}$ of $8.59 \%$. For the temperature range between $230 \mathrm{~K}$ and $310 \mathrm{~K}$ the rate constants calculated from the parameterizations in equations (12) and (14) differ by less than $10 \%$. This is below the uncertainty of the rate constant measurements.

\subsection{Treatment of Source Specific Isotope Fractionation}

[24] In order to get closer insight into the global distribution of ethane from different sources we made MOZART-2 calculations using different species names for the different emission sources, and using the specific $\delta_{\mathrm{S}}$ values from Table 2. Otherwise these tagged ethane emissions were treated using the ethane chemistry presented above. From this calculation we can attribute a typical stable carbon isotope ratio for each source to every air parcel in time and space according to equation (6).

[25] Most sources have stable carbon isotope ratios in the range of $-26 \%$ to $-28 \%$. An exception are emissions from plants using the $\mathrm{C} 4$ path of photosynthesis (C4 plants), which have a quite different source specific isotope ratio of approximately $-13 \%$ and ethane emissions associated with natural gas losses, which are lighter than other fossil fuel consumption related emissions, although the difference is not as pronounced as in the case of methane [Faber, 1987; Berner, 1989]. We split emissions from biomass burning and agricultural waste burning into emissions from $\mathrm{C} 3$ plants and $\mathrm{C} 4$ plants using the global $\mathrm{C} 4$ vegetation percentage map from Still et al. [2003] (Figure 1) and separated natural gas losses from other fossil fuel related emissions. Although the global percentage of $\mathrm{C} 4$ vegetation is only $18 \%$ of the total vegetation it accounts for $31 \%$ of the global MOZART-2 biomass burning emissions. The reason for the higher contribution of emissions from $\mathrm{C} 4$ plants is the frequent and efficient burning of the savannah type landscapes, which have a high percentage of $\mathrm{C} 4$ type vegetation. 

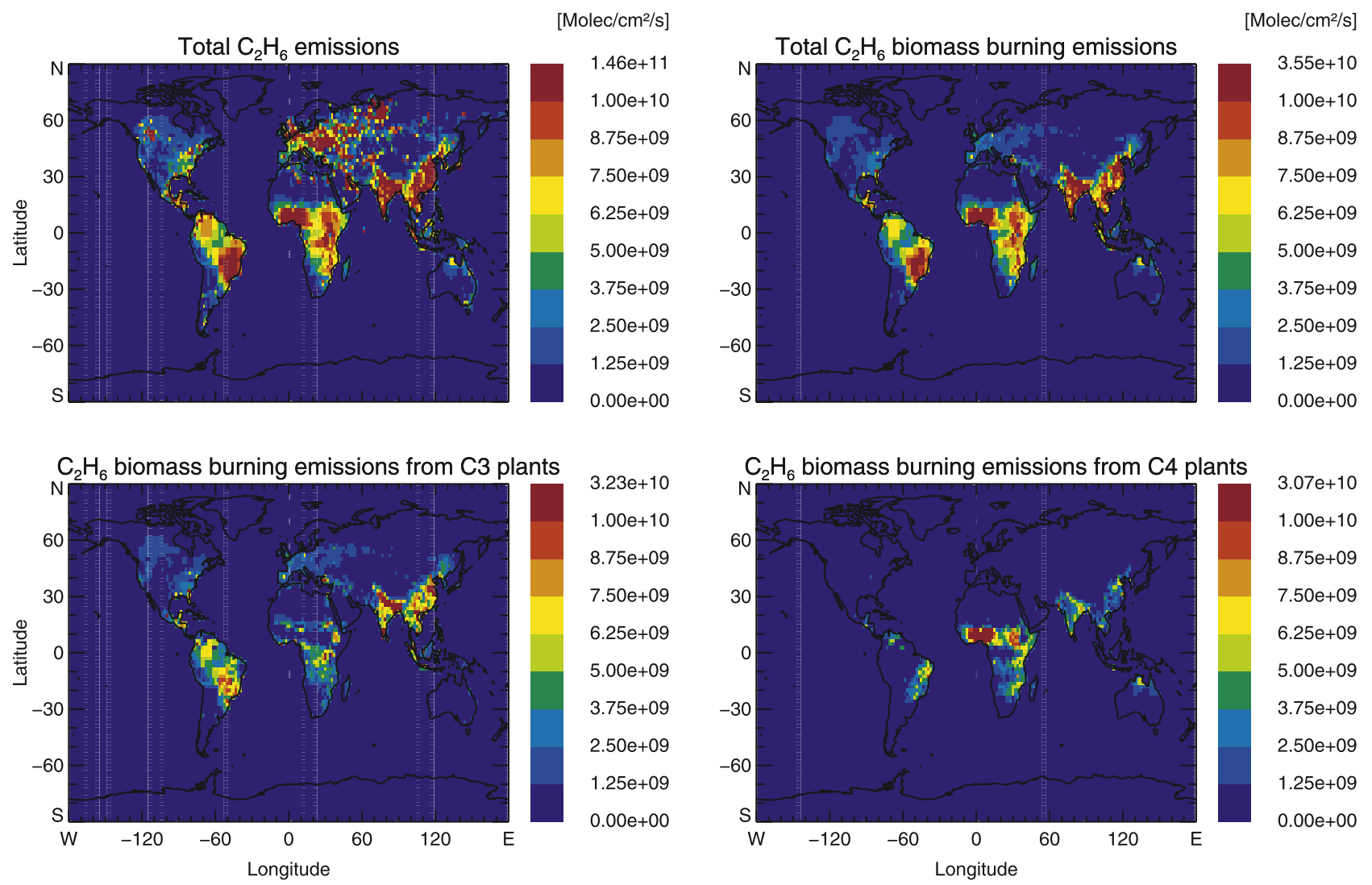

Figure 1. Global distribution of ethane emissions and ethane emissions from biomass burning in MOZART-2. (top left) Total emission rates and (top right) emission rates from biomass burning and contributions from biomass burning of (bottom left) $\mathrm{C} 3$ and (bottom right) $\mathrm{C} 4$ plants based on the global C4 vegetation percentage map from Still et al. [2003].

[26] In Figure 2 we illustrate the stable carbon isotope ratios that could be measured at a receptor site taking into account the effects of isotopic fractionation due to chemical processing and atmospheric mixing $\delta_{\mathrm{a}}$ (Figure 2, top) and due to source specific isotope composition $\delta_{\mathrm{S}}$ (Figure 2, middle). As pointed out before both effects add up to the total isotopic fractionation (Figure 2, bottom). The model result considering only atmospheric fractionation (Figure 2, top) exhibit systematic difference in isotope ratios between source regions and remote areas. The source component of the modeling results distinguishes between regions with sources of different isotope ratios. Specifically the most pronounced structures can be seen for areas with C4-plant biomass burning.

\subsection{Impact of Location of Sources}

[27] The results presented above demonstrate that location of sources and receptor sites has a major impact on the modeled isotope ratio. Therefore we conducted a number of model simulations studying the relation between emissions from specific regions and the large-scale distribution of isotope ratios and concentrations.

[28] MOZART-2 model runs were carried out with emissions limited to selected regions representative for areas with large emissions from different continents: three regions in mid latitudes (Eastern North America, Southern Europe,
East Asia) representative for large anthropogenic emissions and three regions in the tropics (South America, Africa, Southern East Asia) which are dominated by emissions from biomass burning. The location and extent of these emission areas are shown in Figure 3. For these six MOZART scenario runs emissions were held constant at $1 * 10^{10}$ molecules $/ \mathrm{cm}^{2} / \mathrm{s}$ inside each of the defined areas, outside there were no emissions. $1 * 10^{10}$ molecules $/ \mathrm{cm}^{2} / \mathrm{s}$ can be seen as a typical value for areas with major ethane emissions such as Western Europe. Each mid latitude scenario resulted in annual emission rates of $0.376 \mathrm{Tg} / \mathrm{yr}$ ethane; each tropical scenario represents emissions of $0.487 \mathrm{Tg} / \mathrm{yr}$ ethane.

[29] Similarly we conducted model calculations with ethane and ${ }^{13} \mathrm{C}$ ethane emissions limited to 15 latitude bands reaching from $80^{\circ} \mathrm{N}$ to $54^{\circ} \mathrm{S}$. The latitude bandwidth was chosen to correspond to 3 or 4 grid boxes in MOZART-2 that is approximately $8.5-11.4^{\circ}$. Within the specified latitude bands the relative spatial distribution of the sources was kept identical to that in the emission inventory; outside the latitude band all ethane emissions were set to zero. The total emission rate in the latitude band was set to the value of the global emission rate in the original emission inventory. In a postprocessing stage we scaled the emission rates to $1 \mathrm{Tg} / \mathrm{yr}$ for the sake of convenience. These experiments are an extension to the GISS model calculations for ethane 

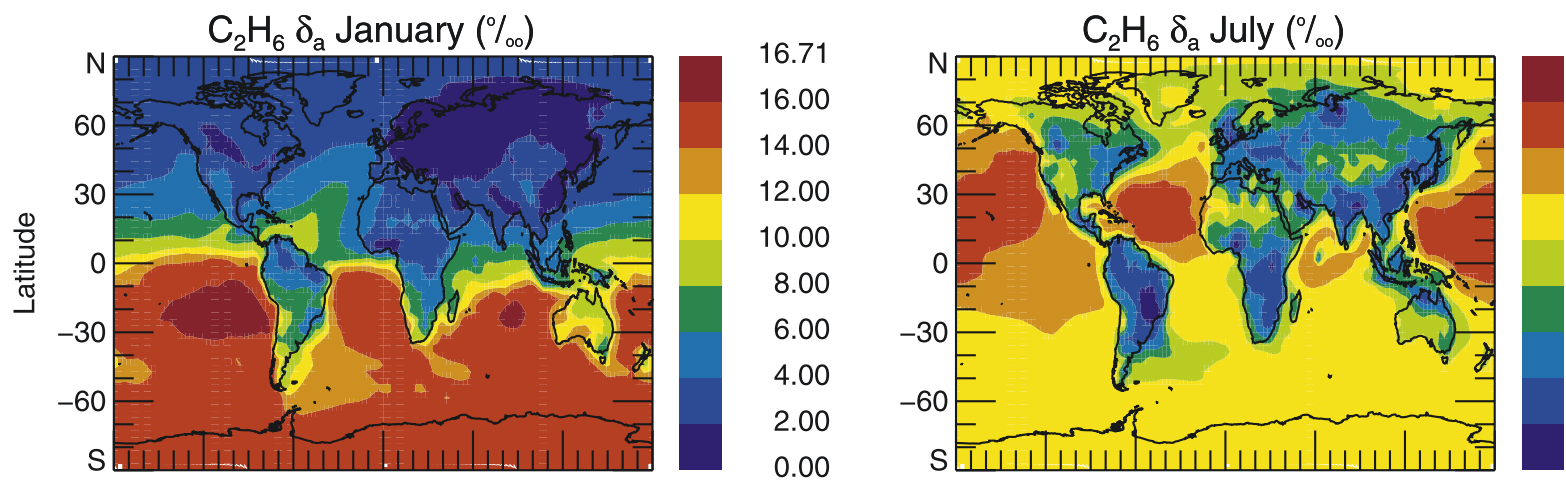

16.00

14.00

12.00

10.00

8.00

6.00

4.00

0.00

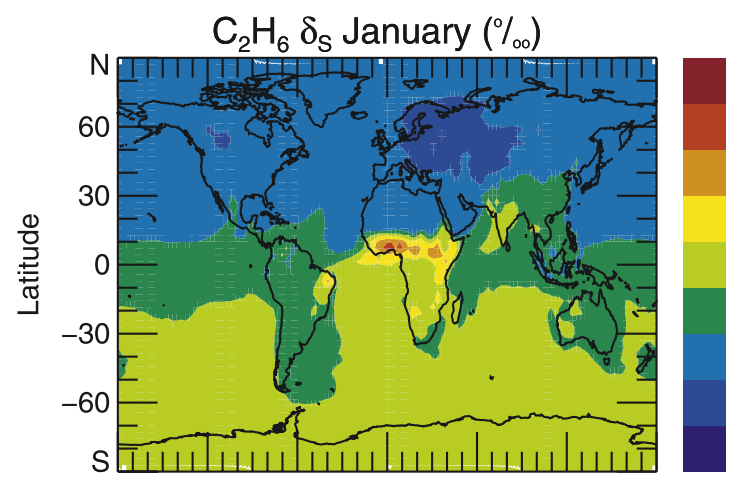

$-16.00$

$-18.00$

$-20.00$

$-22.00$

$-24.00$

$-26.00$

$-28.00$

$-30.00$

$-32.00$

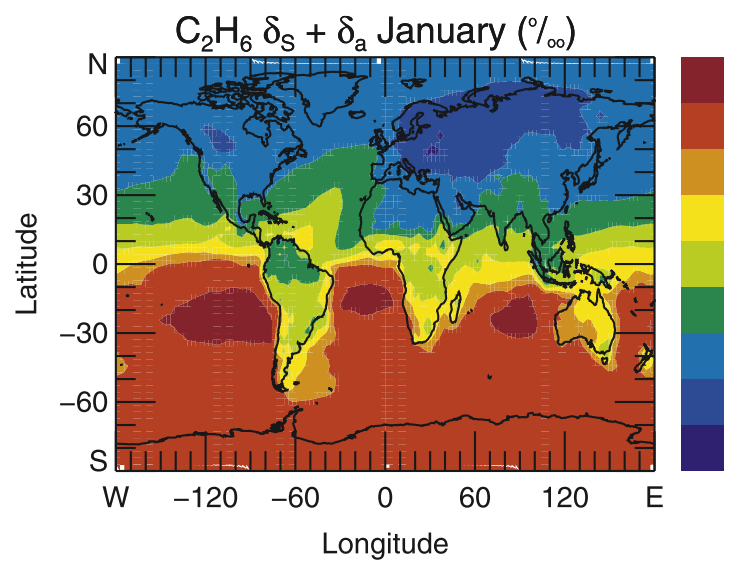

$-7.15$

$-8.00$

$-11.00$

$-14.00$

$-17.00$

$-20.00$

$-23.00$

$-26.00$

$-29.00$

$-32.00$

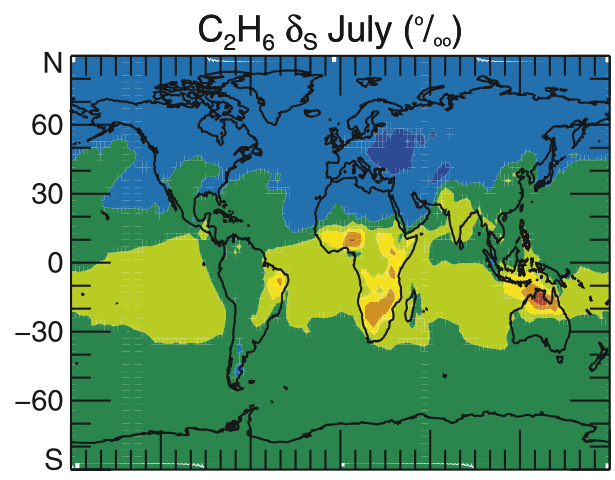

$-15.55$

$-16.00$

$-18.00$

$-20.00$

$-22.00$

$-24.00$

$-26.00$

$-28.00$

$-30.00$

$-32.00$

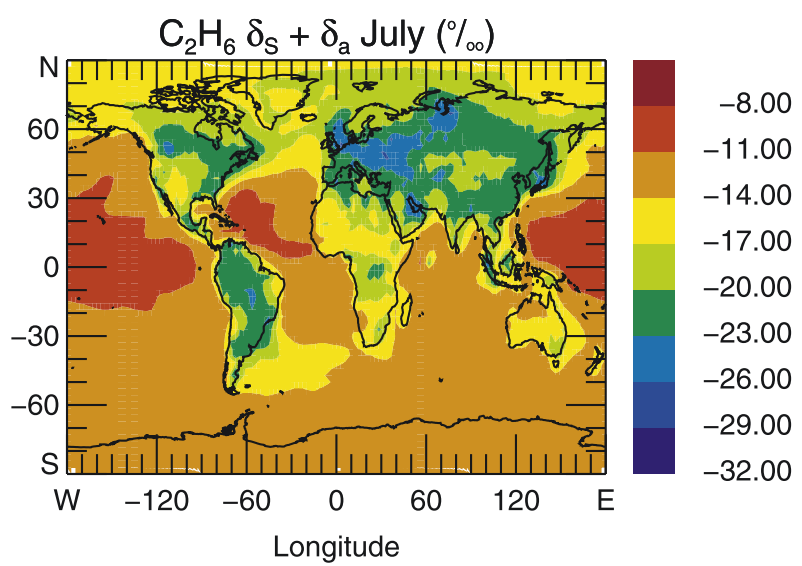

Figure 2. Stable carbon isotope ratios of ethane in January and July 1995 near the surface calculated using MOZART-2 (lowest level, approximately lowest $80 \mathrm{~m}$ above ground). (top) Change in stable carbon isotope ratios due to isotope fractionation from atmospheric processing of ethane $\left(\delta_{\mathrm{a}}\right)$ and (middle) the stable carbon isotope ratios arising from the atmospheric mixing of sources with different isotopic source signatures in the absence of isotope fractionation from reactions in the atmosphere $\left(\delta_{\mathrm{S}}\right)$. (bottom) Combined effects from sources and atmospheric isotope fractionation $\left(\delta_{\mathrm{S}}+\delta_{\mathrm{a}}\right)$.

from Gautrois et al. [2003] adding stable carbon isotopes and now using MOZART-2 instead of the GISS-CTM.

\section{Results and Discussion}

\subsection{Comparison of Model Results and Observations}

[30] In order to differentiate between the impact of model specific parameters such as advection or integration schemes and input data specific for ethane, such as emissions fields or seasonal variability of sources we will compare the output from the two different models as well as runs of MOZART based on meteorological data for different years. Furthermore the different model predictions will be compared with observations.

[31] The GISS and the MOZART-2 CTM differ in horizontal and vertical resolution, use different meteorological fields, treat chemical feedbacks differently, and do not use identical emission rates and source distribution. Figures 4 and 5 present the ethane mixing ratios and atmospheric isotope fractionation, which is the atmospheric ethane isotope ratio calculated for emissions with delta values of zero. To simplify the comparison we scaled the global emissions in the GISS model to the MOZART-2 value, 


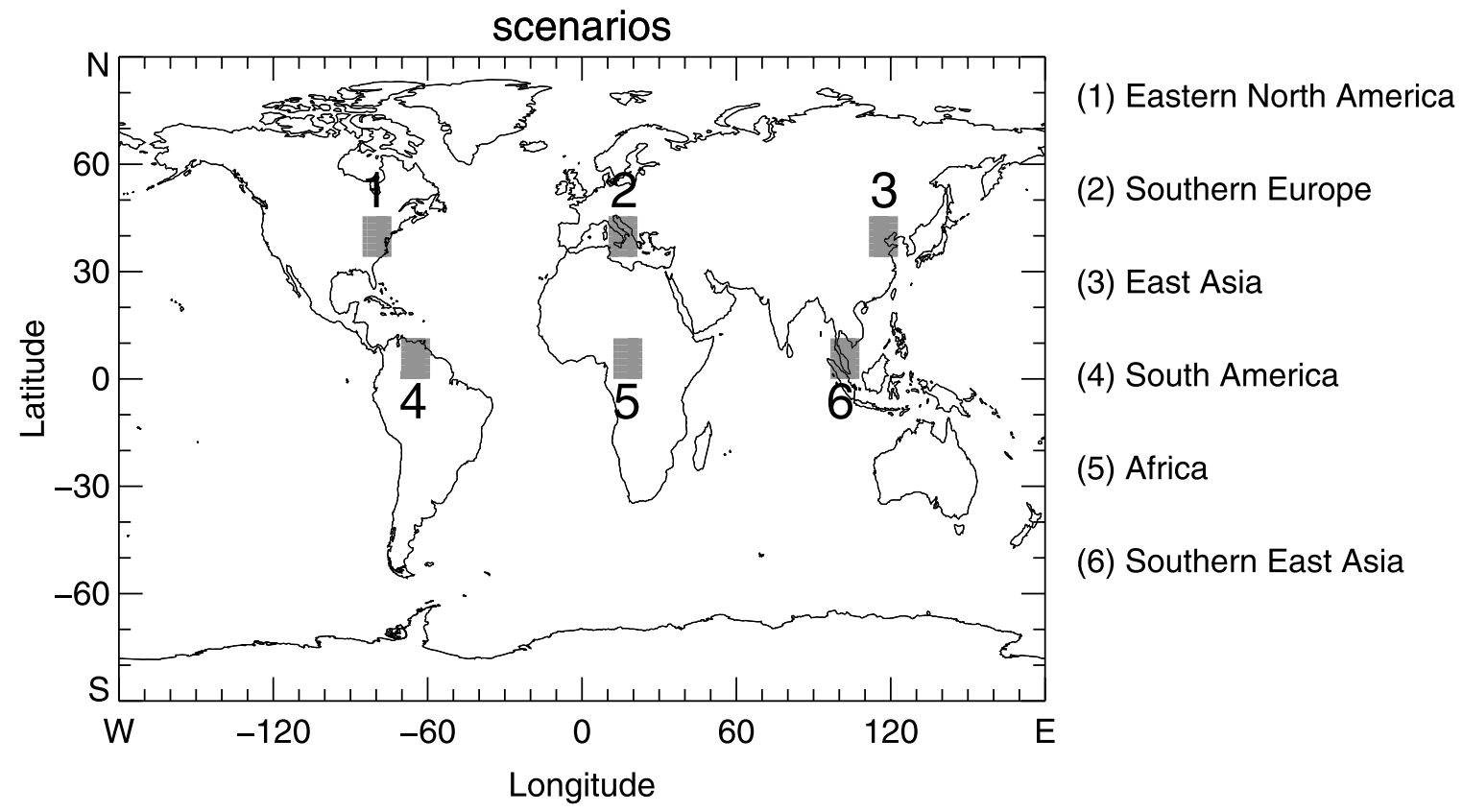

Figure 3. Location of the areas used for regional emission scenario runs. For each of the six scenarios $1-6$, emissions rates were held constant at $1 * 10^{10}$ molecules $/ \mathrm{cm}^{2} / \mathrm{s}$ within the emission region, and outside the specified region emission rates are set to zero.

without changing the geographical distribution of the sources. The resulting GISS ethane mixing ratios are thus $17 \%$ higher than those based on the original EDGAR-2 emissions. Furthermore the MOZART-2 results presented in Figures 4 and 5 are from a run without seasonal variability of the ethane emission rates. This makes them directly comparable to the GISS model. Since the models have different vertical resolutions we averaged the MOZART results over the lowest four levels (ground level to approximately $700 \mathrm{~m}$ ) to obtain compatibility with the lowest GISS level which reaches from the surface to a pressure level of approximately $934 \mathrm{hPa}$.

[32] The main features of the GISS and MOZART-2 ethane mixing ratio fields near the surface are very similar. Both models show similar maximum concentrations in winter over industrialized regions and over major gas and oil fields, and similar latitudinal gradients and seasonal variations. The most apparent difference is the prediction of higher January mixing ratios by MOZART-2 for regions with high ethane emissions such as Eastern Europe, Siberia, the Middle East, or Central Canada and Equatorial Africa. These small, but nevertheless clearly visible differences are mainly due to the different emission inventories used. The higher horizontal resolution in the MOZART-2 model and the different representation of meteorology also can result in higher peak concentrations. There is also some variation between the model results for individual MOZART years (Figure 4, bottom). However, for both years all prominent features are identical and the differences are limited to minor changes in location and extent for areas with enhanced mixing ratios.

[33] The atmospheric fractionation fields from GISS and MOZART-2 are depicted in Figure 5. It should be noted that the results in Figure 5 only present changes in isotope ratios due to atmospheric reactions $\left(\delta_{\mathrm{a}}\right)$. The impact of possible changes in isotope ratios between different types of sources $\left(\delta_{\mathrm{S}}\right)$ is not considered. Nearly all main features of the global distribution are in very good agreement. The absolute values are nearly identical, which indicates that treatment of $\mathrm{OH}$ reactions and global transport at the timescales relevant for ethane are similar in both models. The only significant difference can be found over the Atlantic in the latitude range between $10^{\circ} \mathrm{N}$ and $30^{\circ} \mathrm{N}$. For July MOZART-2 predicts an ethane isotope fractionation of $14 \%$ or more stretching from the African coast to the coast of Florida and the Caribbean. In the GISS model results the region with ethane fractionation of $14 \%$ or more is limited to a very small area off the coast of Florida. Instead there is a gradient in ethane isotope fractionation starting with approximately $10 \%$ close to the African coast. Since a larger isotope fractionation is the consequence of a higher degree of atmospheric processing of ethane, the difference between the two models indicates a difference in either the $\mathrm{OH}$ radical concentration or the timescales of transport for this region.

[34] Comparisons of measurements and model calculations [Thompson et al., 2003; Gautrois et al., 2003] found that model predictions based on the EDGAR-2 emission inventory substantially underestimate the atmospheric ethane mixing ratios. Both studies used the GISS model, but our finding that overall GISS and MOZART-2 agree very well in their prediction of ethane mixing ratios and stable carbon isotope ratios strongly suggests that the main source of the discrepancy between model and observation is an underestimate of ethane emissions by the EDGAR-2 inventory. This will be discussed in more detail in section 4.3.

[35] There is a limited number of stable carbon isotope ratio measurements, which can be compared with the model 

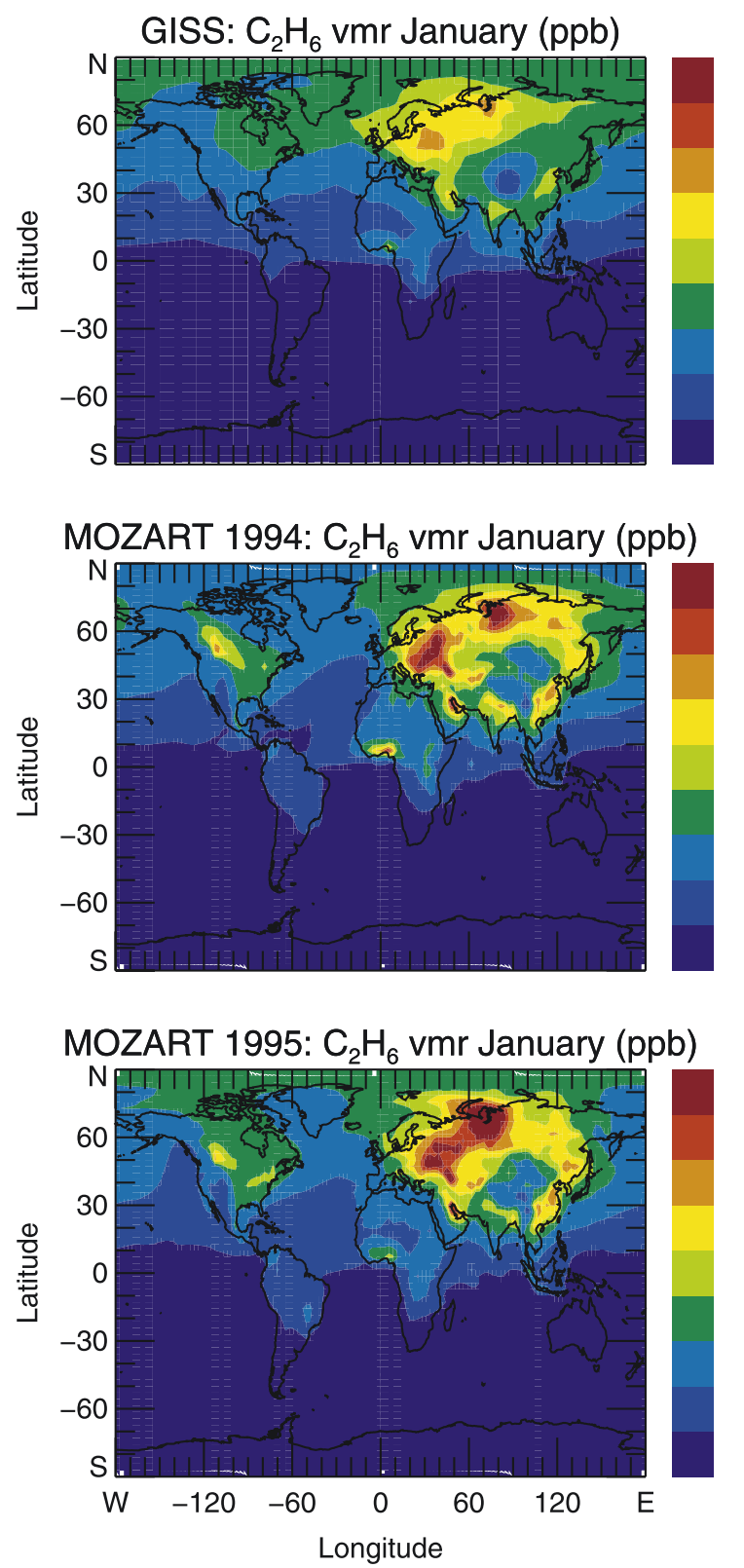

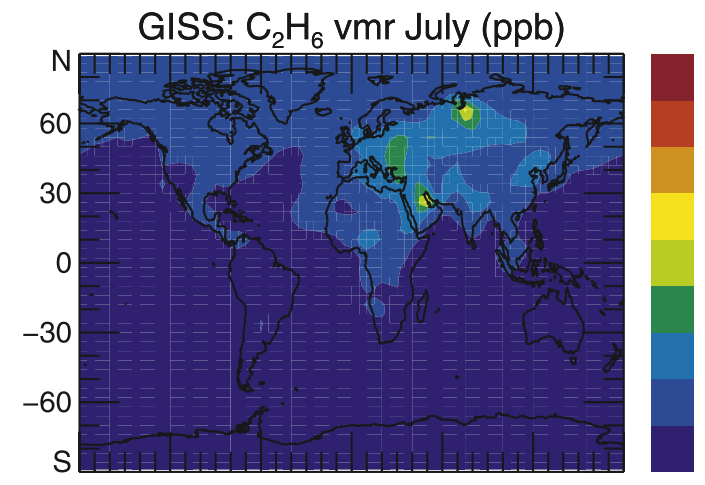

4.00

3.50

3.00

2.50

2.00

1.50

1.00

0.50

0.00
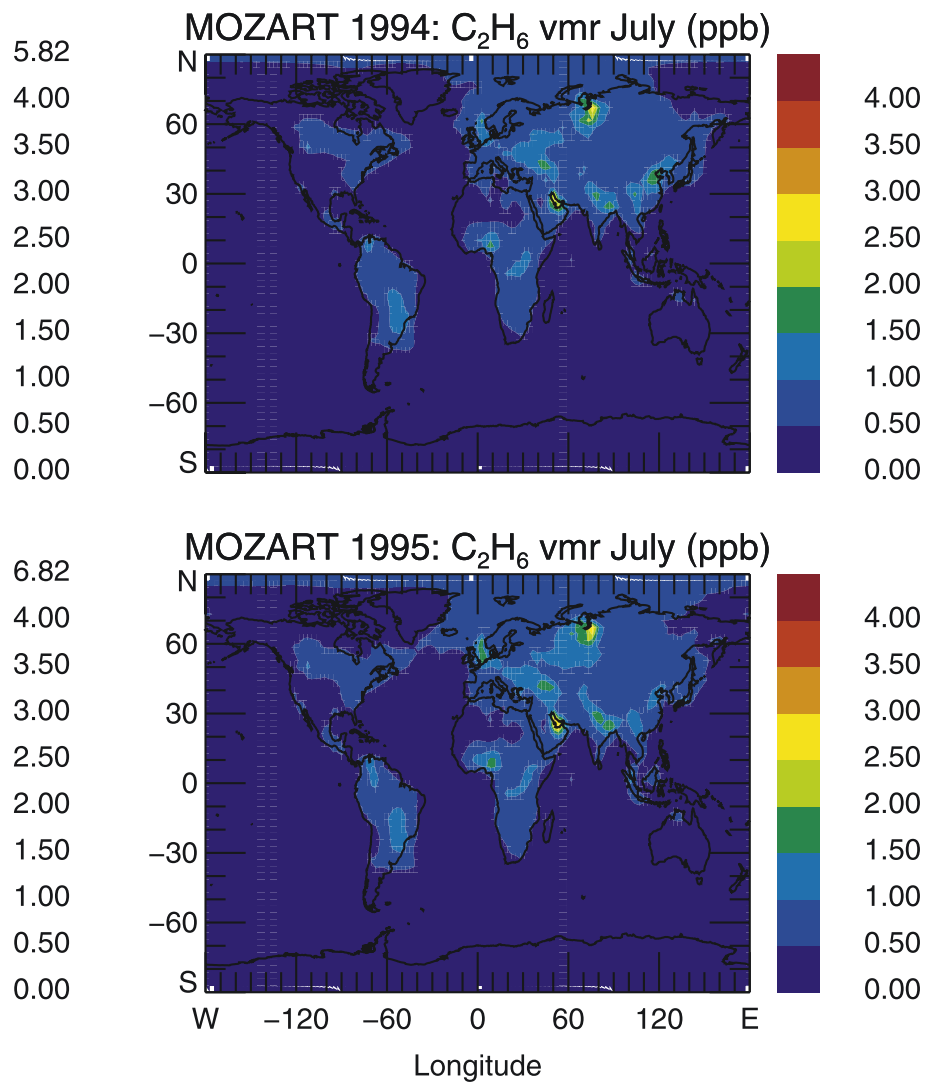

4.00

3.50

3.00

2.50

2.00

1.50

1.00

0.50

0.00

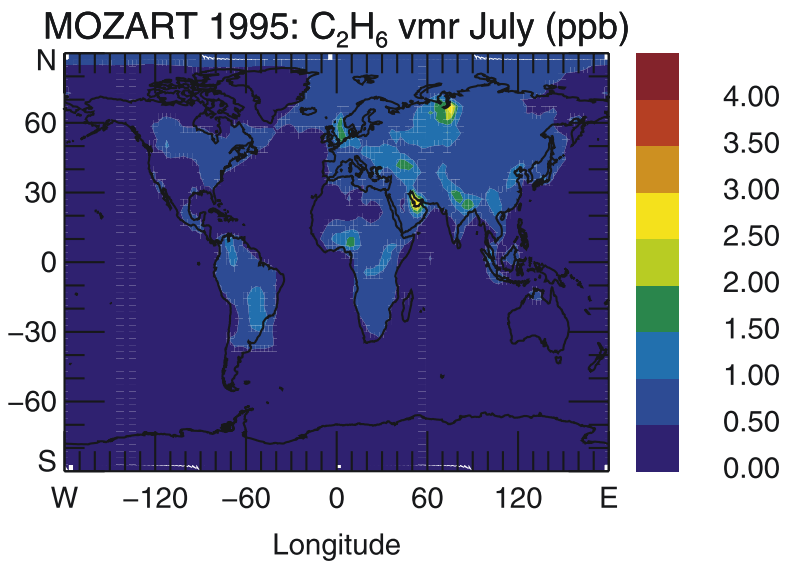

Figure 4. Comparison of modeled ethane volume mixing ratios near the surface (approximately lowest $700 \mathrm{~m}$ ) between (top) GISS and (middle and bottom) MOZART-2. The MOZART-2 results were calculated without seasonal variation of the emission rates. The MOZART-2 results are based on the transport fields for 1994 (middle) and 1995 (bottom).

predictions. Rudolph et al. [1997] report a few measurements of ethane stable carbon isotope ratios from coastal sites in New Zealand. The reported values are in the range of $-22 \%$ to $-29.7 \%$, with an average of $-26.3 \%$. These values are substantially lower than the model predictions, which are in the range of $-14 \%$ to $-20 \%$. However, these measurement results were not filtered with respect to a possible impact of local sources and therefore may have been influenced by nearby emissions. Tsunogai et al. [1999] report a set of measurements for the Pacific south of Japan for March. The observed ethane $\delta^{13} \mathrm{C}$ values increase from approximately $-27 \%$ at $30^{\circ} \mathrm{N}$ to $-21 \%$ at $6^{\circ} \mathrm{N}$. This is in good agreement with the results of the model calculations for January (Figure 2), even so the model predicts a slightly steeper latitudinal gradient. Similarly, the ethane carbon isotope ratios reported by Saito et al. [2002] for $40-50^{\circ} \mathrm{N}$ and $140-165^{\circ} \mathrm{E}$ for May range from $-19 \%$ to $-26 \%$ with an average of approximately $-23 \%$. Again, this is fully consistent with the model predictions. There are also a few observations from urban areas [Rudolph et al., 1997; Tsunogai et al., 1999]. The reported isotope ratios are close to the isotopic composition of fossil fuel. This is consistent with the predictions of our model that the isotope ratios in regions with strong sources are similar to the isotope ratio of the emissions. Overall there is reasonable agreement between measurements and model predictions for the 


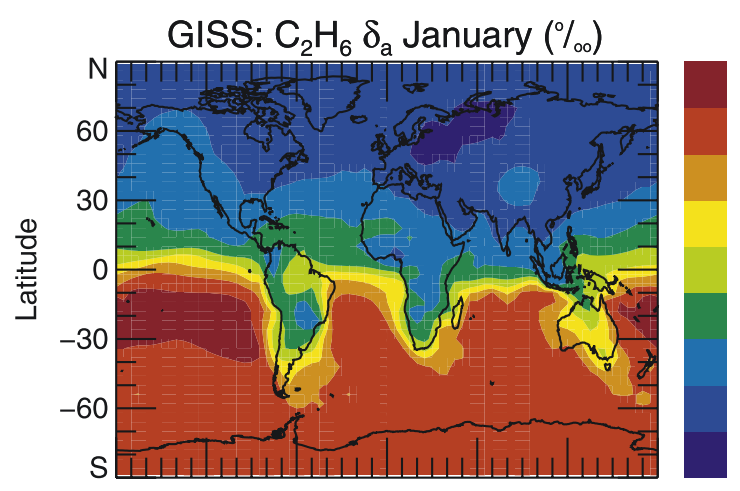

18.21
16.00
14.00
12.00
10.00
8.00
6.00
4.00
2.00
0.00

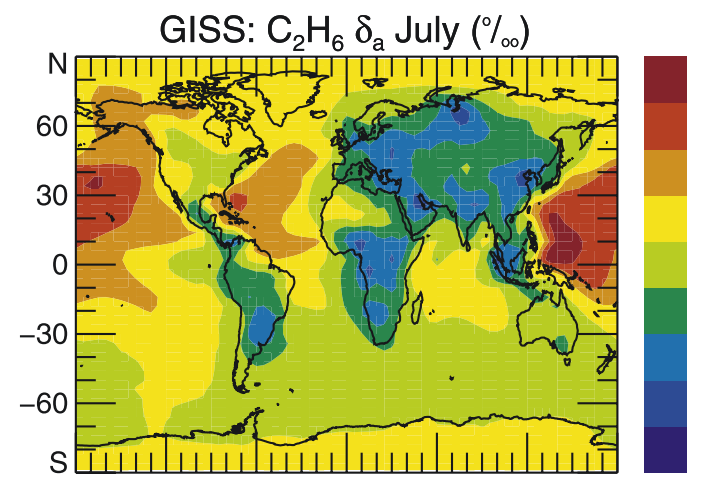

17.80

16.00

14.00

12.00

10.00

8.00

6.00

4.00

2.00

0.00

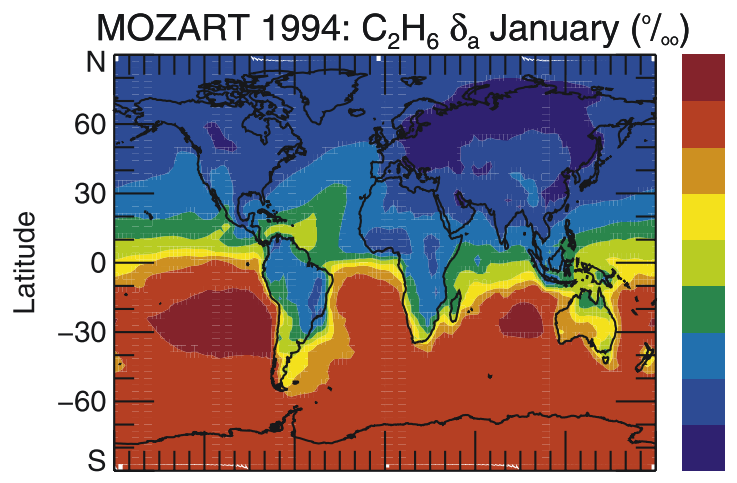

16.89
16.00
14.00
12.00
10.00
8.00
6.00
4.00
2.00
0.00

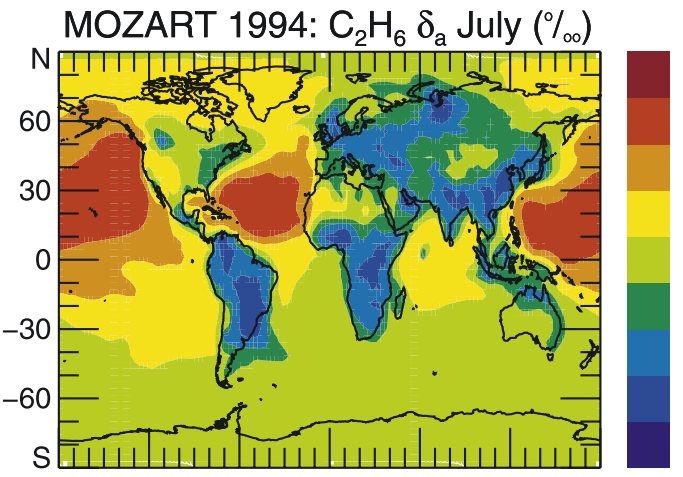

16.00

14.00

12.00

10.00

8.00

6.00

4.00

2.00

0.00
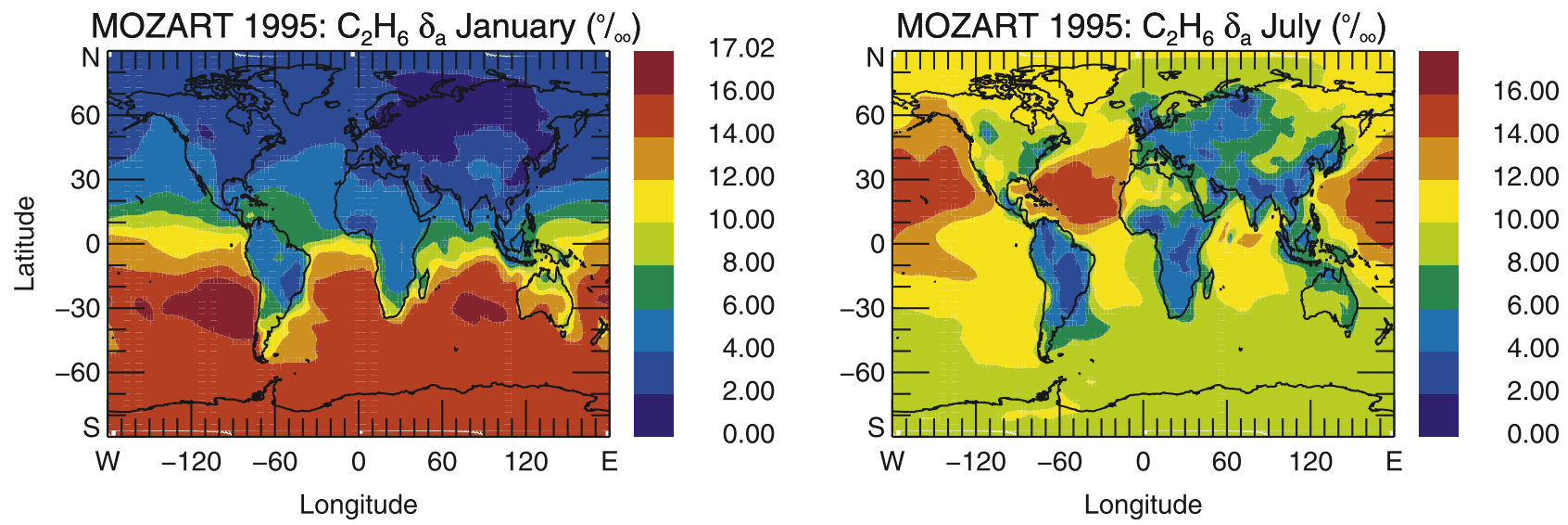

Figure 5. Comparison of ethane stable carbon isotope ratios near the surface (approximately lowest $700 \mathrm{~m}$ ) between (top) GISS and (middle and bottom) MOZART-2. The isotope ratios shown are relative to emissions with a stable carbon isotope ratio of zero \%o. The MOZART-2 results were calculated without seasonal variation of the emission rates. The MOZART-2 results are based on the transport fields for 1994 (middle) and 1995 (bottom).

isotope ratios, but the presently available measurements are too few to allow any firm conclusions about the consistency between model and observations.

\subsection{Emissions From Individual Regions}

[36] In contrast to scaling all emission rates by the same factor, changing emission rates for specific source types or source areas will also change the predicted isotope ratios. Therefore we will have a more detailed look at the dependence between the geographical distribution of emissions and the modeled global ethane mixing ratio and stable carbon isotope ratio.
[37] Near-surface ethane mixing ratio fields from the six MOZART-2 scenario runs are shown for January and July in Figures 6 and 7, the corresponding atmospheric isotope fractionations $\delta_{\mathrm{a}}$ in Figures 8 and 9. The mixing ratio patterns mirror the main atmospheric transport features on the ethane lifetime scale of several weeks to a few months. Because of the short lifetime in summer, the gradients are steeper than in winter (Figures 6 and 8). For emissions in tropical regions (scenarios 4-6) the area of impact changes from $\mathrm{NH}$ to SH between January and July. The regions of maximum ethane mixing ratios also correspond to areas with no or very little isotope fractionation. In principle, the 


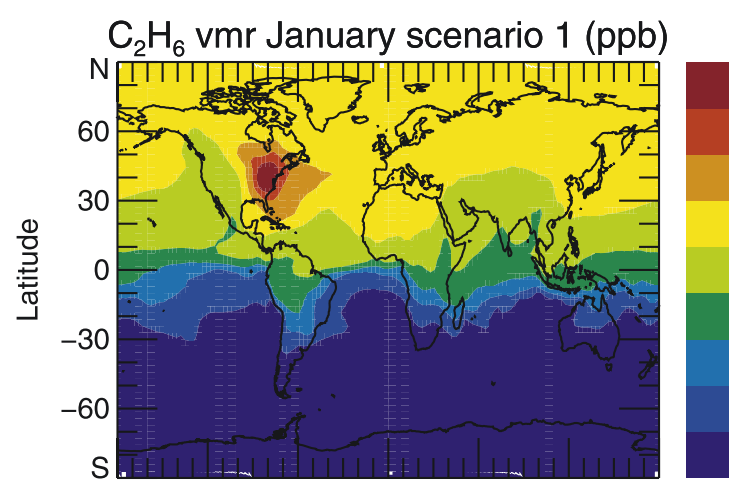

0.833
0.398
0.158
0.063
0.025
0.010
0.004
0.002
0.001
0.000
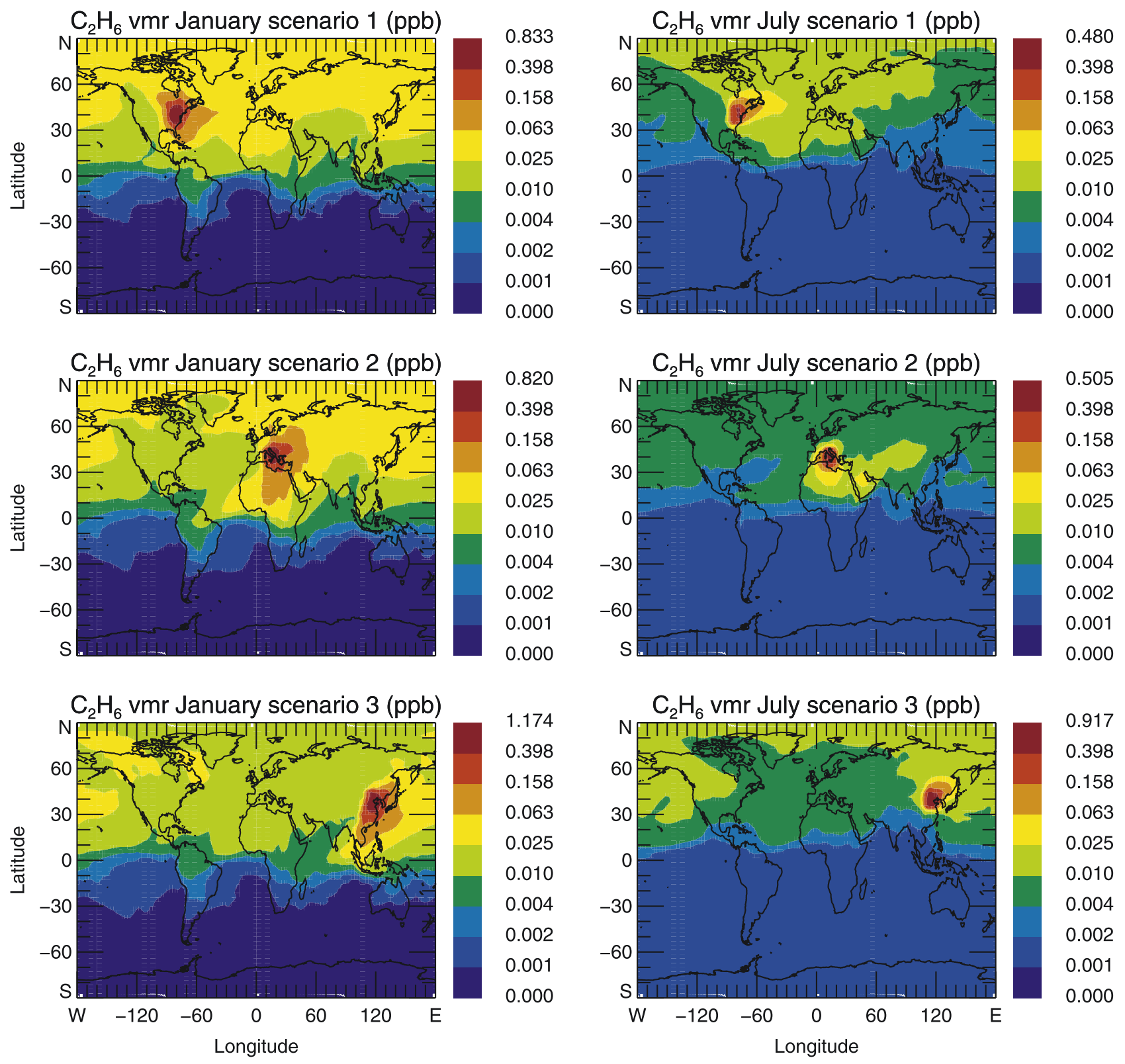

Figure 6. Modeled January and July $\mathrm{C}_{2} \mathrm{H}_{6}$ mixing ratios near the surface for emission scenarios $1-3$ (lowest four levels, approximately lowest $700 \mathrm{~m}$ above ground).

most dominant features for the scenarios with emissions in the same latitude band are very similar: outside of the source areas strong gradients are only found along the intertropical convergence zone (ITCZ). For scenarios at mid northern latitudes $(1-3)$ mixing ratios in the Northern Hemisphere exceed those in the Southern Hemisphere by more than an order of magnitude, a consequence of the fact that the average atmospheric residence time of ethane is short compared to the timescale for interhemispheric exchange. For the same reason the stable carbon isotope fractionation in the Southern Hemisphere is 20-28\%o, approximately $15-20 \%$ higher than for the Northern Hemisphere.

[38] Qualitatively the high degree of correspondence between gradients in mixing ratios and gradients in isotope fractionation suggests that chemical processing, which deter- mines the extent of isotope fractionation (equation (4)), is the primary driving force for the changes in ethane mixing ratios. However, quantitative considerations, which allow a more detailed insight, present a far more differentiated picture. In the absence of mixing and dilution the dependence between stable carbon isotope ratio and mixing ratio can be described by the Rayleigh function

$$
\delta_{t}=\left(\delta_{0}+1\right) \cdot\left(\frac{[H C]_{t}}{[H C]_{0}}\right)^{\frac{-\varepsilon_{O H}}{1+\varepsilon_{O H}}}-1
$$

where $\delta_{0}$ and $[\mathrm{HC}]_{0}$ are the initial isotopic composition and mixing ratio and $\delta_{\mathrm{t}}$ and $[\mathrm{HC}]_{\mathrm{t}}$ are the isotopic composition and mixing ratio at time $t$.

[39] The other extreme case, where mixing dominates and chemical processing has no directly visible impact, can be 

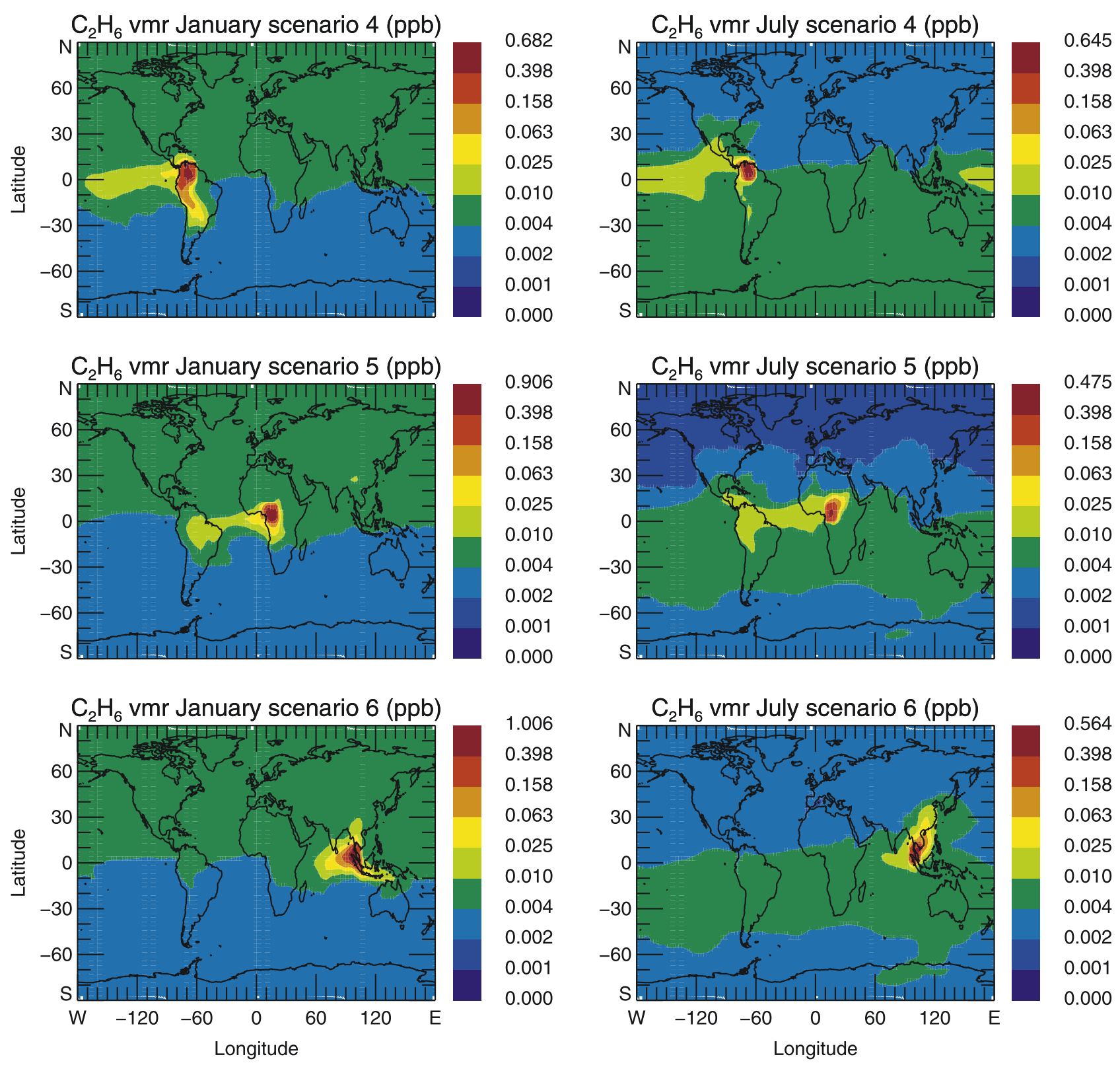

Figure 7. Modeled January and July $\mathrm{C}_{2} \mathrm{H}_{6}$ mixing ratios near the surface for emission scenarios 4-6 (lowest four levels, approximately lowest $700 \mathrm{~m}$ above ground).

described by a two endpoint mixing type function. For an emission of ethane with a stable carbon isotope ratio of $\delta_{\mathrm{E}}$ into an air mass with concentration $[\mathrm{HC}]_{\mathrm{B}}$ and stable carbon isotope ratio $\delta_{\mathrm{B}}$ the dependence between the resulting stable carbon isotope ratio $\delta_{\mathrm{t}}$ and concentration $[\mathrm{HC}]_{\mathrm{t}}$ follows a function similar to two-endpoint-mixing curves:

$$
\delta_{t}=[H C]_{B} /[H C]_{t} \cdot\left(\delta_{B}-\delta_{E}\right)+\delta_{E}
$$

[40] For the case of simplicity we used $\delta_{\mathrm{E}}=0$ for our scenario calculations and therefore equation (16) simplifies to:

$$
\delta_{t}=[H C]_{B} /[H C]_{t} \cdot \delta_{B}
$$

[41] It should be noted that the difference between $\delta_{\mathrm{B}}$ and $\delta_{\mathrm{E}}$ is due to isotope fractionation during chemical loss reactions. Thus the two-endpoint-mixing curve (17) will represent the regime dominated by dilution of the emissions with background air while the Rayleigh function (15) describes the change of isotope ratios under conditions where the change in concentration is dominated by chemical loss. Indeed, there are two different regimes distinguishable in Figures 6-9. To demonstrate this in more detail, Figure 10 shows examples for the dependence between mixing ratio and stable carbon isotope ratio based on individual grid points. For comparison Rayleigh and two-endpoint-mixing functions are also shown. The background values $[\mathrm{HC}]_{\mathrm{B}}$ and $\delta_{\mathrm{B}}$ used in the two endpoint mixing curves are chosen as the Northern Hemispheric mean (scenario 2) and the global mean (scenario 6) of these variables. 


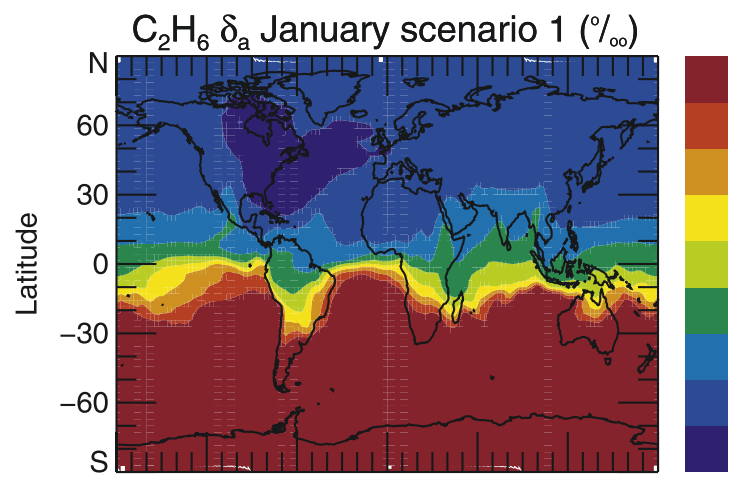

28.74
20.00
17.50
15.00
12.50
10.00
7.50
5.00
2.50
0.00

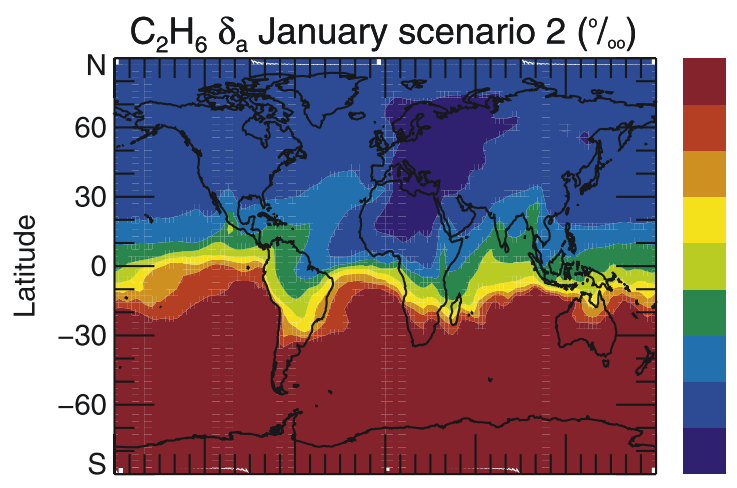

27.19

20.00

17.50

15.00

12.50

10.00

7.50

5.00

2.50

0.00

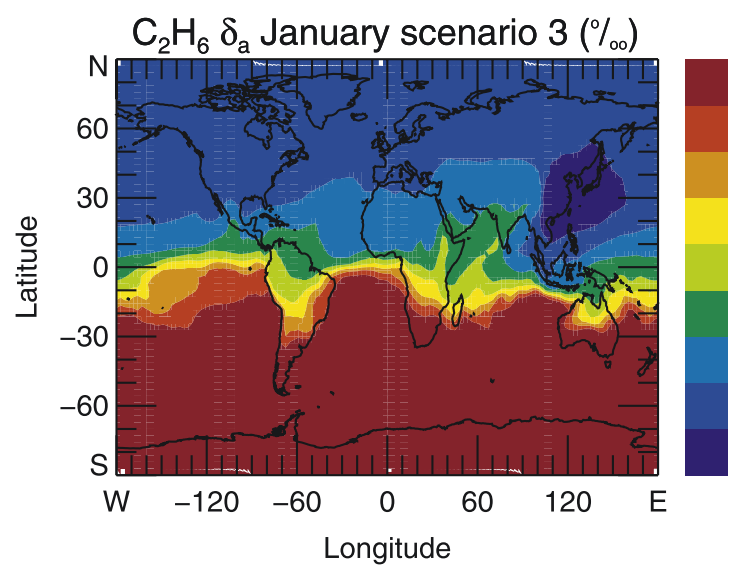

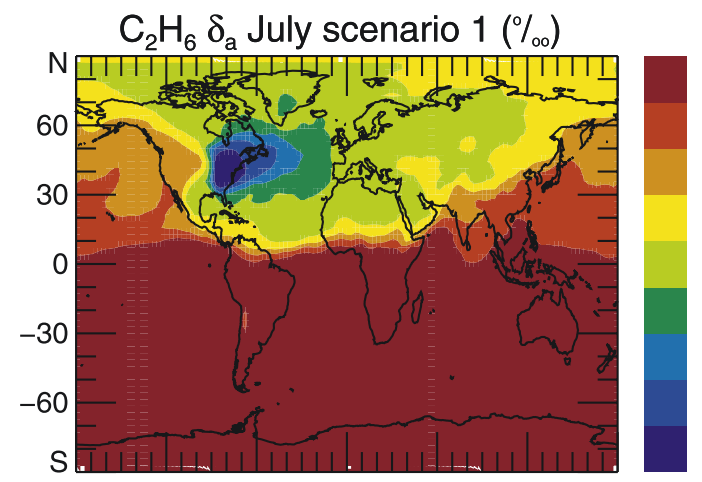

23.27

20.00

17.50

15.00

12.50

10.00

7.50

5.00

2.50

0.00
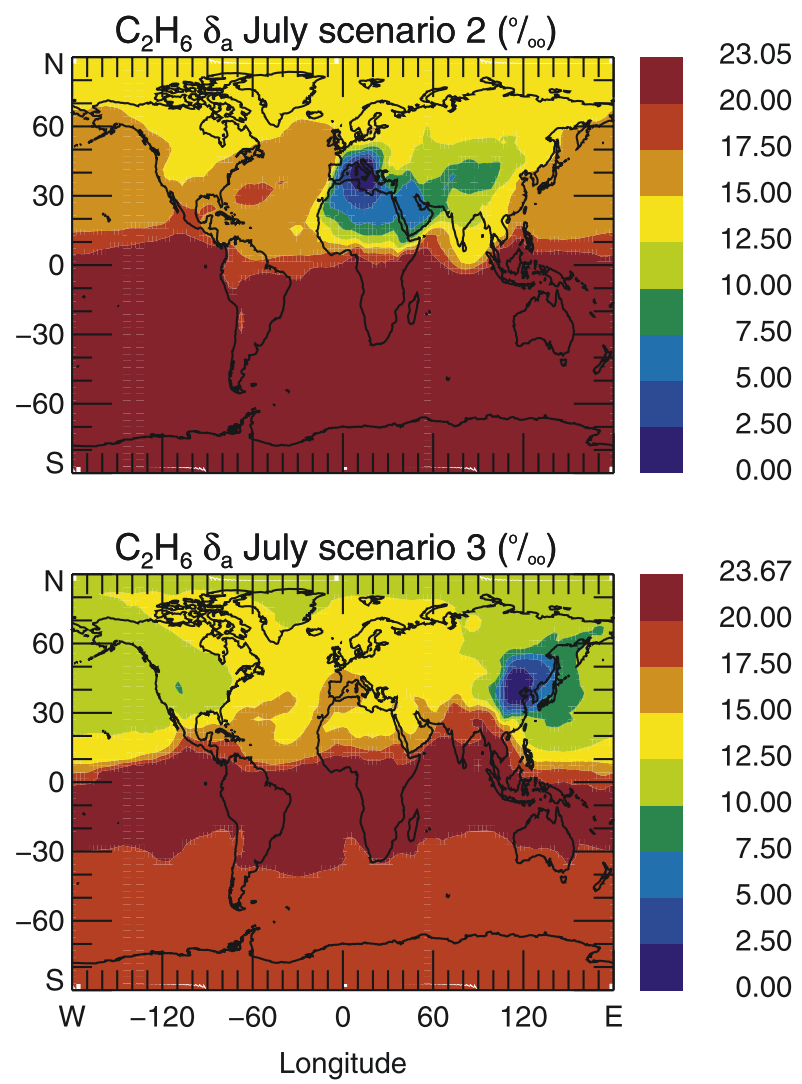

Figure 8. Modeled January and July $\mathrm{C}_{2} \mathrm{H}_{6}$ stable carbon isotope ratios $\delta_{\mathrm{a}}$ near the surface from emission scenarios 1-3 (lowest four levels, approximately lowest $700 \mathrm{~m}$ above ground).

[42] While the exponent of the Rayleigh function is unambiguously defined by the KIE of the reaction $\left(\varepsilon_{\mathrm{OH}}\right)$ there is no obvious, entirely objective choice for the value of $[\mathrm{HC}]_{0}$. For the Rayleigh curve in scenario 6 we used the mean mixing ratio for the latitude band $10^{\circ} \mathrm{S}-21^{\circ} \mathrm{N}$. For the mid latitude emission scenario three Rayleigh curves are shown for comparison: For January $[\mathrm{HC}]_{0}$ is chosen as the mean mixing ratio for the latitude band $0-3^{\circ} \mathrm{N}$, for July the mean mixing ratio for the whole Northern Hemisphere (left curve), and the mean mixing ratio for the latitude band $34-46^{\circ} \mathrm{N}$ (right curve) are used. In January only the mixing ratios near the equator seem to be relevant for the Southern Hemisphere values. In July we have to differentiate between the northern and the Southern Hemisphere: a mean $[\mathrm{HC}]_{0}$ from the whole Northern Hemisphere seems to fit the functional dependency best in the Southern Hemisphere while at high northern latitudes the mean from the latitude band where the emissions are situated gives a better description of the data points.

[43] For the latitude range where the emissions occur it is obvious that mixing dominates and the dependence between concentration and stable carbon isotope ratio can be approximated by equation (17). For example during summer for scenarios $1-3$ the mixing ratios and stable carbon isotope ratios at mid northern latitudes outside of regions directly impacted by the emissions are in the range of 4-10 ppt and 10-16\%o, respectively. On the basis of these values and the peak mixing ratios over the source region of approximately $0.5 \mathrm{ppb}$, the two-endpoint-mixing function (17) predicts a stable carbon isotope ratio of 

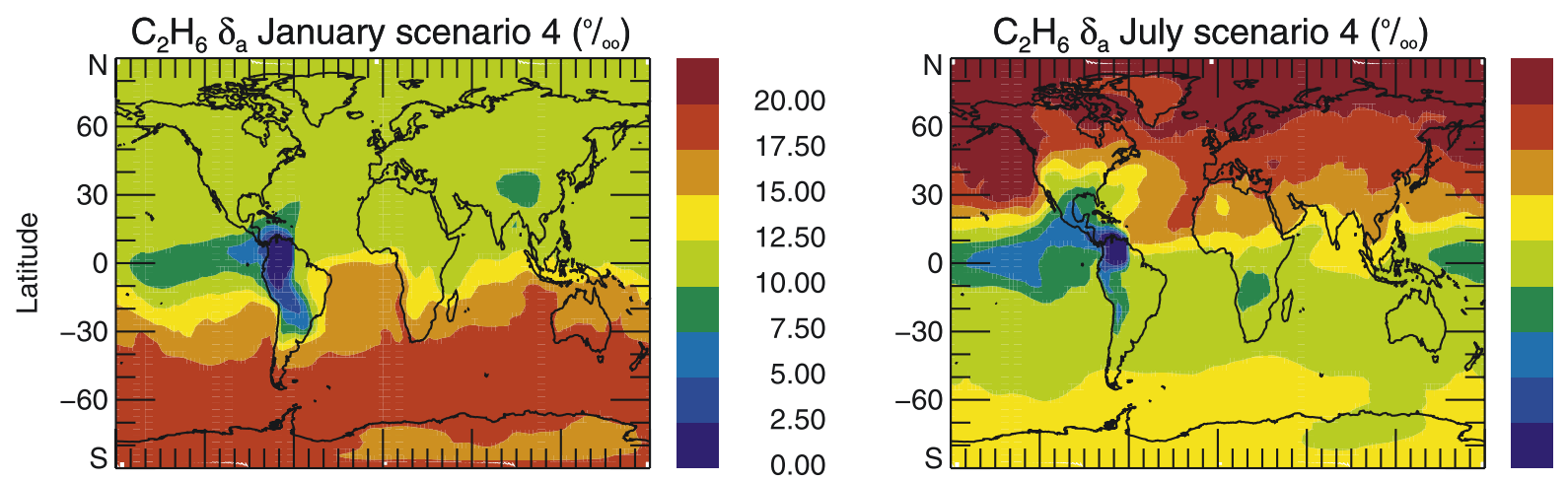

20.00

17.50

15.00

12.50

10.00

7.50

5.00

2.50

0.00

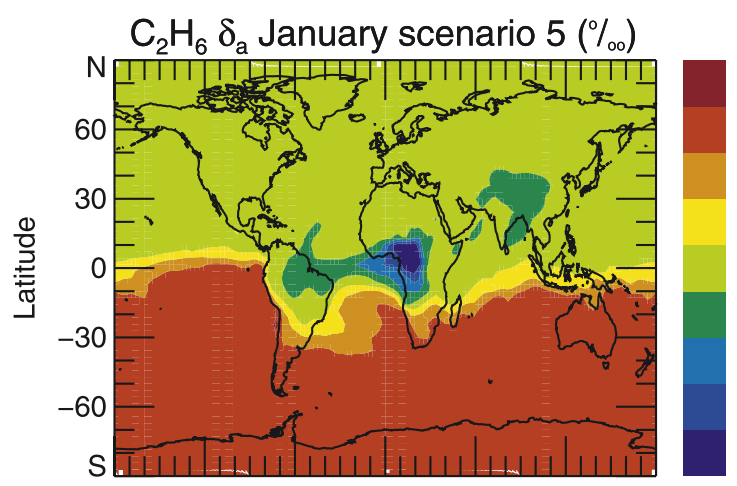

20.23

20.00

17.50

15.00

12.50

10.00

7.50

5.00

2.50

0.00
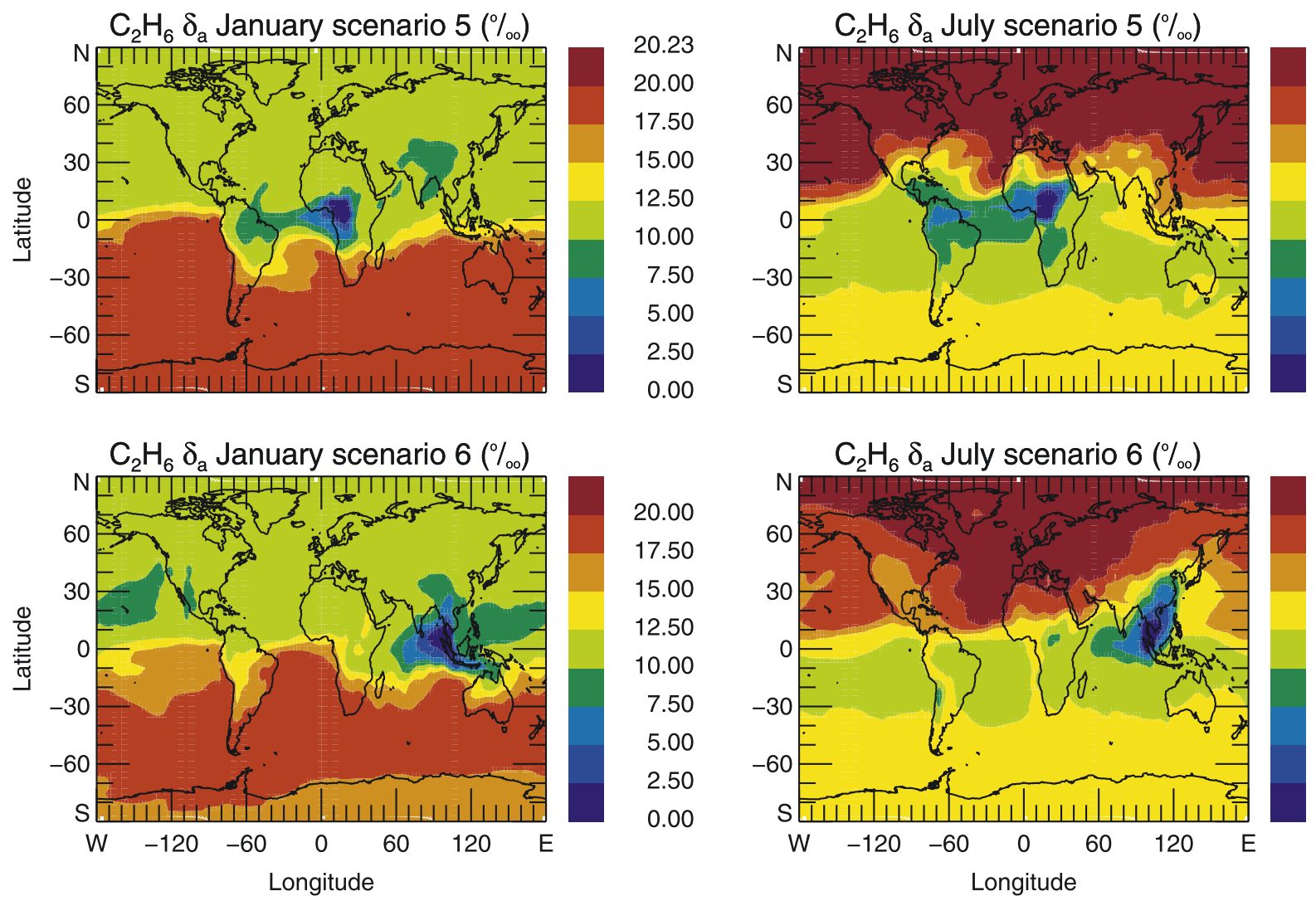

23.72

20.00

17.50

15.00

12.50

10.00

7.50

5.00

2.50

0.00

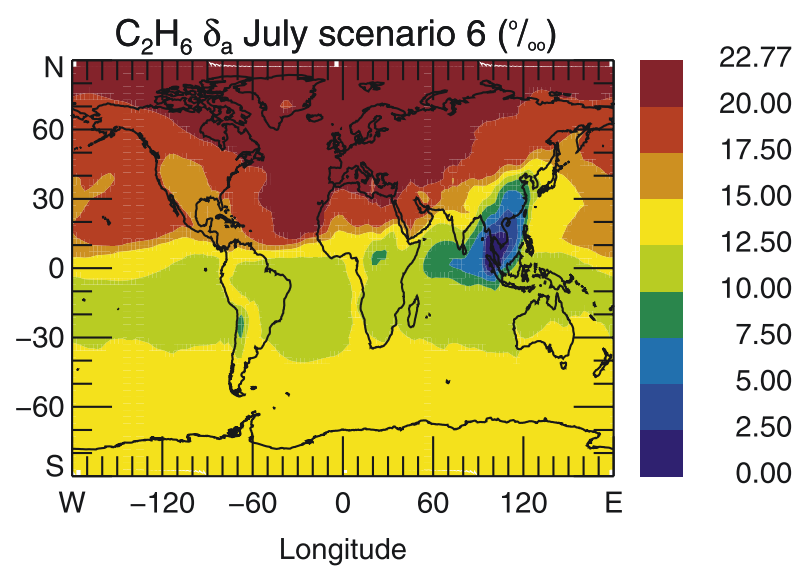

Figure 9. Modeled January and July $\mathrm{C}_{2} \mathrm{H}_{6}$ stable carbon isotope ratios $\delta_{\mathrm{a}}$ near the surface from emission scenarios 4-6 (lowest four levels, approximately lowest $700 \mathrm{~m}$ above ground).

$0.1-1.5 \%$ for the emission region. This is fully compatible with the isotope ratios of $0-2 \%$ found over the source regions (Figure 8). In contrast to this the Rayleigh dependence (15) predicts a difference of approximately 30-40\%o between background and source region, clearly not compatible with the model results.

[44] For scenario 2 (Southern European emissions, Figure 10, top) the dependence between mixing ratio and stable carbon isotope ratio in January indicates a very significant influence of mixing for effectively all extra tropical northern latitudes, while the curve approaches a Rayleigh function at mid and high latitudes of the Southern Hemisphere. In July this behavior is less pronounced but still visible. When increasing the distance from the emission latitude the slope of the curve gets steeper changing from a mixing curve dependence at mid northern latitudes to a
Rayleigh behavior at low latitudes and in the Southern Hemisphere. It is interesting to note that in July a Rayleigh type function also describes the dependence at high northern latitudes. This indicates that for sources at mid northern latitudes chemical processing dominates the dependence between mixing ratio and stable carbon isotope ratio in these regions. Figure 10 (bottom) refers to scenario 6 (South East Asian emissions). Again the curves show dependencies resembling Rayleigh functions for remote areas, while mixing dominates in the tropics.

[45] In some cases (scenario 3 for July and scenarios 4-6 for January) the atmospheric fractionation becomes slightly lower if we go to high southern latitudes. Since in our scenarios the ethane emissions in the Southern Hemisphere are zero, this points toward transport processes bypassing the surface level regions with high fractionation between the 

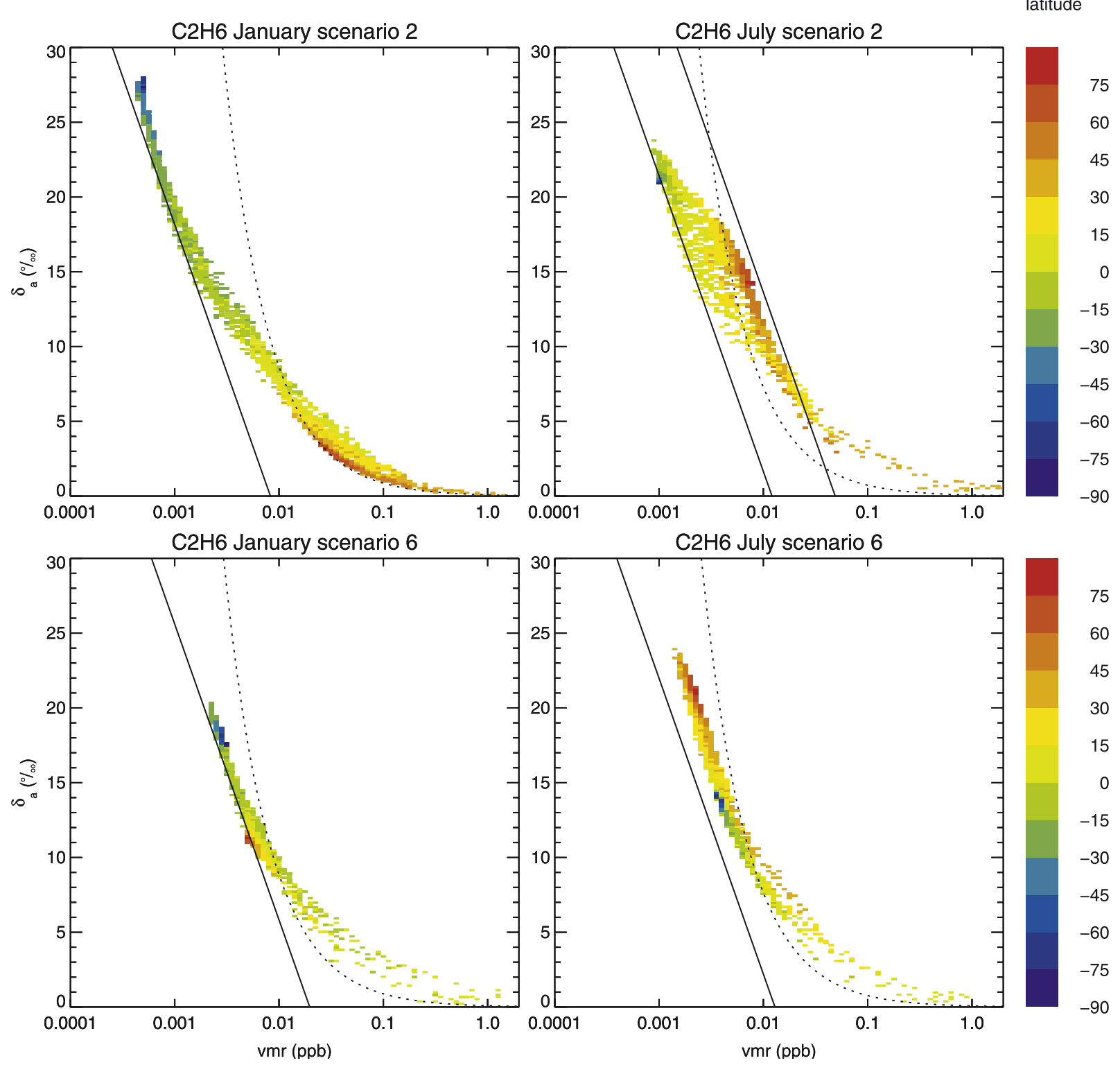

Figure 10. Dependence between mixing ratios and stable carbon isotope ratios of ethane for all lowest level grid points (approximately from 0 to $80 \mathrm{~m}$ above ground) for emission scenarios 2 and 6 . The solid lines show the dependence predicted by the Rayleigh equation based on different values for $[\mathrm{HC}]_{0}$. The dotted lines show two endpoint mixing curves based on average background values for the Northern Hemisphere (scenario 2) or global mean isotope ratios (scenario 6). The colors identify the latitude band of the grid point results.

receptor regions and the sources, e.g., by vertical transport through convection in the tropics and then horizontal transport at higher altitudes. It is interesting that there is no indication for a corresponding increase in mixing ratios. This suggests that during such a transport process dilution is more effective than chemical loss at lower altitudes.

\subsection{Emissions From Individual Latitude Bands}

[46] The results of the studies of emissions from individual regions suggest that there is relatively fast mixing within a given latitude band. Thus on a large scale it seems justified to use zonal averages to extract the most important features of global distributions. This was done for the modeling experiments with emissions limited to individual latitude bands. It allows a compact representation of the dependence between latitude of emission and average mixing ratio or isotope ratio at the latitude of observation (Figure 11).

[47] Figures $11 \mathrm{a}-11 \mathrm{~d}$ show the zonally averaged mixing ratios and isotope ratios for the lowest model level as function of the latitude at which the emissions occur. Figures $11 \mathrm{e}-11 \mathrm{~h}$ present the variability of mixing ratios and isotope ratios within the latitude band as function of the latitude of the emissions. In order to allow a comparison between emissions at different latitudes, the mixing ratios are scaled to an emission rate of $1 \mathrm{Tg} / \mathrm{yr}$ for each latitude band. It should be noted that the normalization does not 

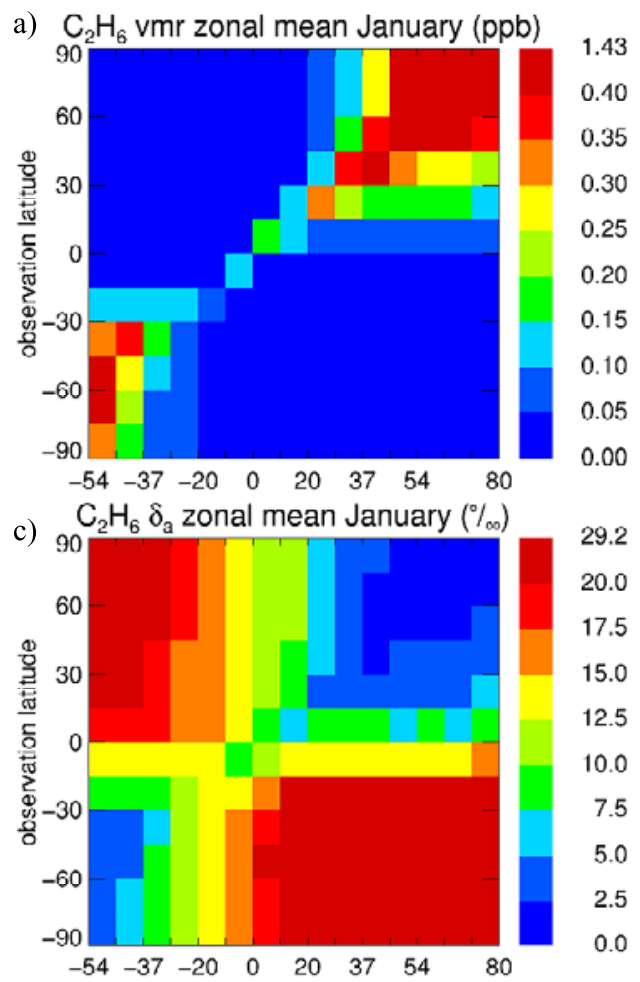

e) $\mathrm{C}_{2} \mathrm{H}_{6}$ vmr zonal rel. stddev January (\%)

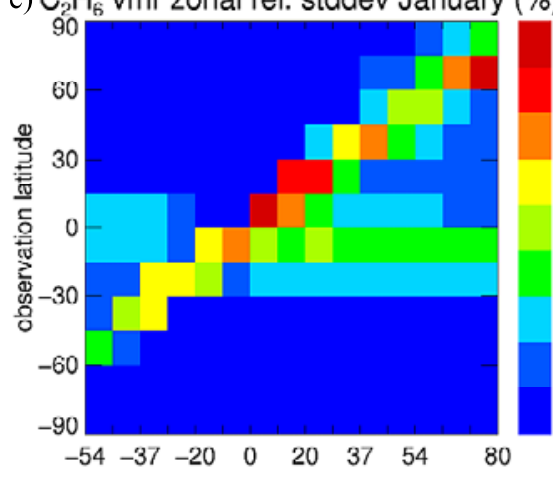

g) $\mathrm{C}_{2} \mathrm{H}_{6} \delta_{\mathrm{a}}$ zonal abs. stddev January $\left(\% \%_{0}\right)$

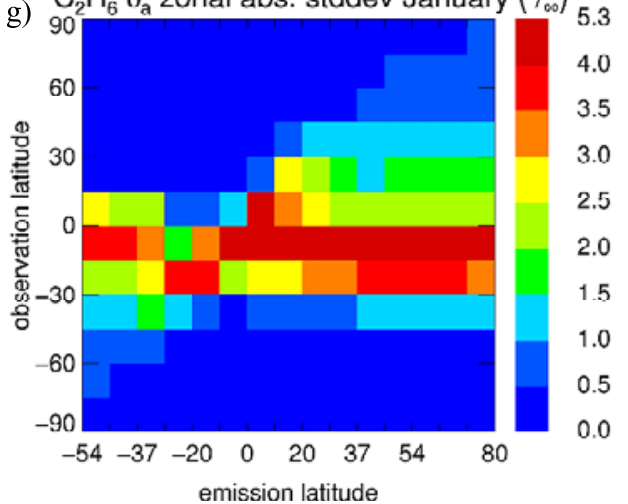

b) $\mathrm{C}_{2} \mathrm{H}_{6}$ vmr zonal mean July (ppb)

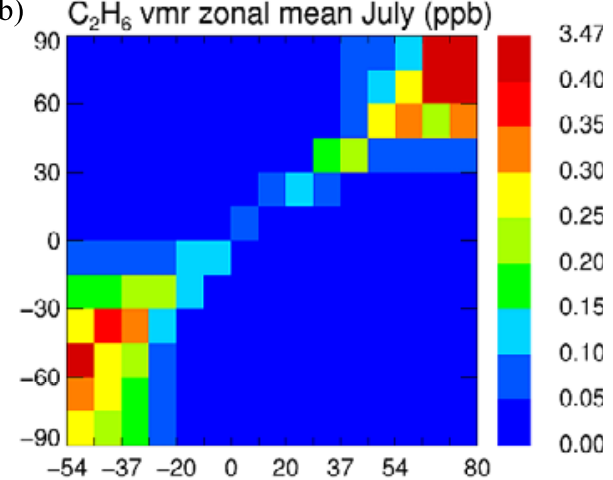

d) $\mathrm{C}_{2} \mathrm{H}_{6} \delta_{\mathrm{a}}$ zonal mean July $(\%)$

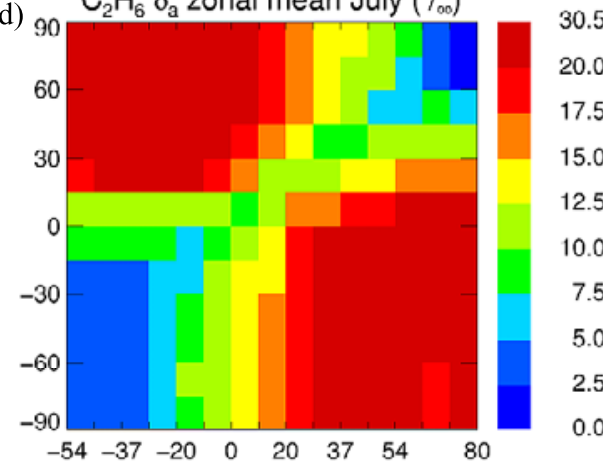

f) $\mathrm{C}_{2} \mathrm{H}_{6}$ vmr zonal rel. stddev July (\%)

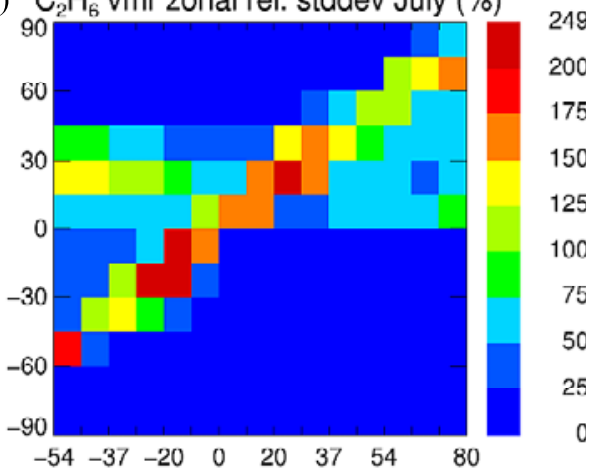

$\mathrm{C}_{2} \mathrm{H}_{6} \delta_{\mathrm{a}}$ zonal abs. stddev July $(\%)$

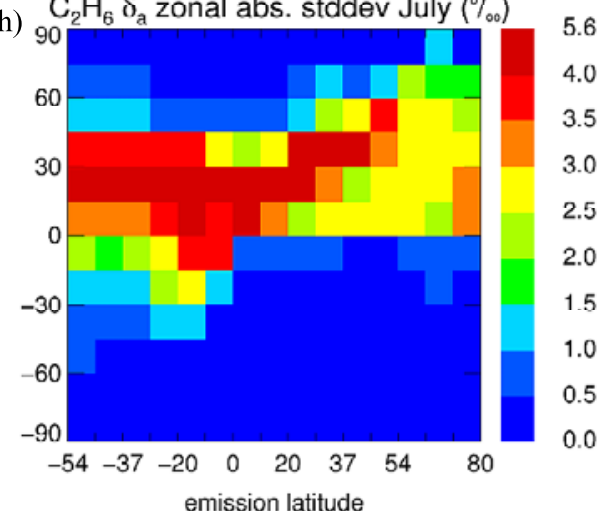

Figure 11. (a-d) Zonal averages for the lowest level of MOZART-2 model and (e-h) relative standard deviations of the volume mixing ratios and standard deviations of the stable carbon isotope ratios. The isotope ratios presented are relative to the isotope ratios of the emissions. Dependence of atmospheric volume mixing ratio (Figures 11a, 11b, 11e, and 11f) and stable carbon isotope ratios (Figures 11c, 11d, $11 \mathrm{~g}$, and $11 \mathrm{~h}$ ) on latitude of emission is shown. For each of the 15 emission scenarios the total emission rate inside the latitude band was set to $1 \mathrm{Tg} / \mathrm{yr}$. Outside of the zone emissions were set to zero. Within the latitude bands the relative distribution of the sources is identical to the source distribution in MOZART-2. 
correct for the differences in area between the individual latitude bands. The most important factor is the dependence of the circumference of the bands on the cosine of latitude. For example a latitude band at $60^{\circ}$ covers only half the area of a zone of identical width at the equator. Furthermore, not all latitude bands are of identical width, however this only results in a relative difference of $\pm 15 \%$. Although the differences in area do not influence the isotope ratios, they have to be considered for comparisons of mixing ratios.

[48] The most obvious feature in Figures $11 \mathrm{a}$ and $11 \mathrm{~b}$ is the limited latitude range which is strongly impacted by emissions from one latitude band. Typically a strong influence of mixing ratios is limited to the latitude band of the emissions and the two adjacent zones. The only major exceptions are found for mid and high latitudes in winter. On average a strong impact on mixing ratios is correlated with low changes in isotope ratio relative to the isotope ratio of the emissions (Figures 11c and 11d). This allows, similar to the previously discussed dependencies between isotope ratios and mixing ratios, differentiation between the influence of dispersion and photochemical removal on the change of mixing ratios. This will be briefly explained using emissions at $0-10^{\circ} \mathrm{N}$ and $20-30^{\circ} \mathrm{N}$ for the month of January. The mixing ratios calculated for the emission latitudes are $0.15-0.2 \mathrm{ppb}$ and $0.3-0.35 \mathrm{ppb}$, respectively. There are three factors, which can contribute to this difference in mixing ratios. As mentioned above, the impact of differences in area between the latitude bands can be derived from simple geometric considerations to approximately $10 \%$, a relatively small contribution to the observed change of nearly a factor two. The isotope ratios change from $7.5-10 \%$ to $2.5-5 \%$. In the absence of mixing effects, a difference of $5 \%$ in isotope ratio corresponds to a relative change in mixing ratios of approximately $40 \%$. This is sufficient to explain the by far largest part of the differences in mixing ratios. This strongly suggests that in this case the different mixing ratios are mainly due to differences in chemical processing and not atmospheric dispersion, which is consistent with the latitudinal gradient in $\mathrm{OH}$ radical concentrations in January [Spivakovsky et al., 2000].

[49] The variability of the mixing ratios (Figures 11e and 11f) shows a diagonal pattern, which is very similar to the behavior found for the mixing ratios and isotope ratios (Figures $11 \mathrm{a}-11 \mathrm{~d})$. The substantial relative variability within the latitude band of the emissions, which often exceeds $75 \%$, can be explained by the patchiness of the sources within the individual latitude bands (Figure 1). This is identical to the finding of areas with strongly enhanced mixing ratios over the source regions as can be seen from a comparison of Figure 1 and Figure 4. Apart from the latitudes of emission and the zones immediately adjacent to the emission latitudes, the relative variability of the mixing ratios is generally less than $25 \%$. The only exception can be found in a zone at low latitudes, where the relative standard deviation frequently exceeds $50 \%$. This band occurs in January in the Southern Hemisphere and in July in the Northern Hemisphere, which suggests that it is related to regions with high $\mathrm{OH}$ radical concentrations and thus a faster removal rate for ethane.

[50] Indeed, these bands of increased variability of the ethane mixing ratio coincide with a zone of increased variability in isotope ratios (Figures $11 \mathrm{~g}$ and $11 \mathrm{~h}$ ). At these latitude bands the variability of the isotope ratios is often in the range of 5\%, which indicates that a significant part of the variability of the mixing ratios results from varying degrees of chemical processing. At mid and high latitudes the variability of the isotope ratios is small, generally below $1 \%$, which indicates that changes in chemical processing do not cause any significant variability of the mixing ratios there.

[51] On the basis of equation (5) the sensitivity of the ethane isotope ratios toward changes in emission rates can be derived by combining results from different emission scenarios, such as latitude dependencies as discussed above, without running new numerical model simulations. However, the sensitivity of the isotope ratio on changes of emissions depends on the mixing ratios as well as on the source isotope ratios for the reference emission scenario. This is in contrast to the sensitivity of mixing ratios toward changes in emission rates. Because of the negligible feedback of the ethane emission rates on the $\mathrm{OH}$ radical concentration (section 4.1) the sensitivity of the ethane mixing ratio toward changes in emission rates do not depend on the base emissions.

[52] The latitude specific dependence between emission rates and zonally averaged mixing ratios can be used to gain insight into the latitudinal distribution and magnitude of additional ethane sources needed to reconcile the discrepancies between model predictions and observations. Figure 12 shows a comparison of zonally averaged mixing ratios derived from observations [Rudolph, 1995] and model results for January and July. It can be seen that MOZART-2 severely underestimates the observations. Only for tropical and midnorthern latitudes in January model and observations agree. It has been suggested [Thompson et al., 2003] that scaling the emission rates to a total of about $18 \mathrm{Tg} / \mathrm{yr}$ will significantly improve the agreement between model and observations. However, as can be seen from Figure 12, model calculations based on such linearly scaled emission rates seriously overestimate the mixing ratios in January for most of the Northern Hemisphere and for July significant differences can be seen at low latitudes and midnorthern latitudes.

[53] Better agreement is found if the increase in emission rates is limited to midsouthern and high northern latitudes. Increasing emissions simultaneously by $0.6 \mathrm{Tg} / \mathrm{yr}$ for midsouthern latitudes and by $1 \mathrm{Tg} / \mathrm{yr}$ for high northern latitudes results in substantially improved agreement between prediction and observation. Only in the latitude range between the equator and $45^{\circ} \mathrm{N}$ for July the discrepancy between prediction and observation exceeds the uncertainty in the observations. Closing the gap between observation and prediction would require a source of approximately $3 \mathrm{Tg} / \mathrm{yr}$ at low northern latitudes. However, such a source would have to peak in spring or early summer and be effectively absent in fall, otherwise the predictions for January would by far exceed the observations.

[54] The presently available global scale distribution of ethane is based on a limited data set and a considerable extent of interpolation. Combined with the uncertainty of existing emission estimates for identified ethane sources this results in substantial uncertainties of the estimates of magnitude and latitudinal distribution of the missing ethane 

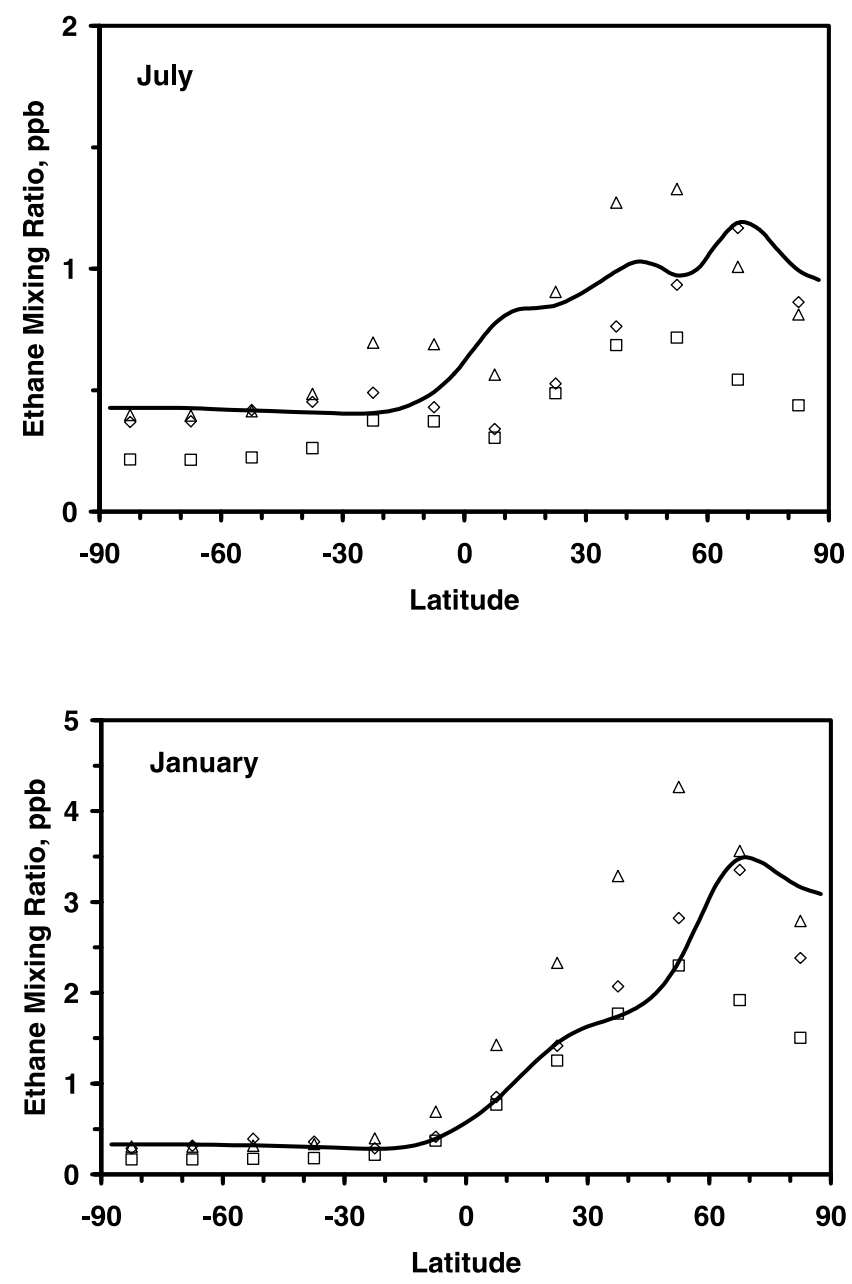

Figure 12. Comparison of observed zonally average ethane mixing ratios from Rudolph [1995] (solid line) with model predictions based on different emission scenarios. Squares indicate MOZART-2 emissions, triangles indicate MOZART-2 emissions scaled linearly to an average of $18 \mathrm{Tg} / \mathrm{yr}$, and diamonds indicate MOZART-2 with an additional source of $0.6 \mathrm{Tg} / \mathrm{yr}$ at mid southern latitudes and $1 \mathrm{Tg} / \mathrm{yr}$ at high northern latitudes.

sources. Nevertheless, overall there is strong evidence that the current emission inventories underestimate the global ethane sources by $4-5 \mathrm{Tg} / \mathrm{yr}$, that is approximately $50 \%$.

\section{Summary and Conclusions}

[55] Model predictions of the isotope ratios of atmospheric ethane show qualitatively many similarities with modeled mixing ratios. The shapes of seasonal cycles, latitudinal gradients, and regions with maximum values very often show close relations between mixing ratios and carbon isotope ratios. However, quantitatively regimes with different dependencies between mixing ratios and isotope ratios can be distinguished. These dependencies fall into the range given by a Rayleigh type function for conditions with a strong dependence between mixing ratios and isotope ratios at one end and two end-point-mixing curves at the other end. Rayleigh type dependence are characteristic for conditions where changes in mixing ratio are primarily driven by atmospheric loss processes; two end-point-mixing behavior is found when atmospheric dilution and mixing dominates.

[56] Our model calculations demonstrate that conceptually the processes determining the isotope ratios of atmospheric VOC can be separated into two components: the isotope ratio of the emissions and the isotope fractionation due to removal processes. This conceptual separation provides the possibility for an objective and quantitative distinction between mixing processes and atmospheric reactions as origin of changes in VOC mixing ratios. Specifically our model calculations demonstrate that comparison between isotope ratios and mixing ratios allows distinction between mixing ratio gradients determined by mixing processes and regions where changes in mixing ratios are dominated by atmospheric processing.

[57] The consistent under prediction of atmospheric ethane mixing ratios by the different model calculations strongly supports previous findings which suggest that current emission inventories underestimate the global ethane emission rates [Thompson et al., 2003; Gautrois et al., 2003]. Effectively all known sources of atmospheric ethane also emit large amounts of various other VOC and often also carbon monoxide and nitrogen oxides or methane. Thus our findings are consistent with recent multimodel [Shindell et al., 2006] and inverse model studies [e.g., Arellano et al., 2004; Pétron et al., 2002, 2004] on global $\mathrm{CO}$, which state a substantial underestimate of $\mathrm{CO}$ emissions in the EDGAR v3.2 inventory, especially over East Asia.

[58] The studies of source receptor relations reveal the existence of simple patterns describing most of the dependence between emission and observation latitudes for mixing ratios as well as isotope ratios. The dependence between calculated zonal averages of mixing ratios and emission latitude allows insight into the latitudinal distribution of the missing ethane source. Consistent with the conclusions of Gautrois et al. [2003] our results show that an increase of high northern latitude ethane emissions by approximately $1 \mathrm{Tg} / \mathrm{yr}$ significantly improves the agreement between model and observations. However, our findings also strongly suggest that additional sources at low latitudes of the Northern Hemisphere and at mid latitudes of the Southern Hemisphere are required to obtain agreement between model predictions and observations. The comparison suggests that the overall underestimate of ethane sources in current inventories is in the range of $50 \%$. As mentioned above, effectively all known types of ethane sources also emit other important trace gases. However, the type and magnitude of such emissions will be highly dependent on the nature of the unidentified source. For example Gautrois et al. [2003] hypothesized that the unidentified high-latitude ethane emissions are due to natural gas losses. Since methane is the main component of natural gas whereas ethane only constitutes a small percentage of natural gas, this implies that high-latitude methane emissions are underestimated by several ten $\mathrm{Tg} / \mathrm{yr}$.

[59] Comparisons of model predictions and observations allow estimates of the magnitude and latitude range of unidentified sources, but provide only indirect evidence for the type of sources. In many cases isotope ratio studies 
can be used to obtain additional evidence for the identity of the source. For example ethane from natural gas is lower in source specific isotopic fractionation than oil or coal derived emissions and emissions derived from biomass containing C4 plant material such as savannah grasses or corn based bio fuels will be enriched in ${ }^{13} \mathrm{C}$ compared to most other sources of VOC.

[60] Our modeling calculations used ethane as example for a global study of the mixing ratios and carbon isotope ratios of atmospheric VOC. We expect that similar systematic dependencies between mixing ratios and isotope ratios can be found for other VOC and other stable isotope ratios, although at temporal and spatial scales which will depend on the atmospheric residence time of the individual VOC.

[61] Acknowledgments. This work was partly funded by the German BMBF AFO-2000 project ISOTROP, the Natural Sciences and Engineering Research Council (NSERC) of Canada, and the Canadian Foundation for Climate and Atmospheric Sciences (CFCAS).

\section{References}

Anderson, R. S., L. Huang, R. Iannone, A. E. Thompson, and J. Rudolph (2004), Carbon kinetic isotope effects in the gas phase reactions of light alkanes and ethene with the $\mathrm{OH}$ radical at $296 \pm 4 \mathrm{~K}$, J. Phys. Chem. A, $108,11,537-11,544$.

Andreae, M. O., and P. Merlet (2001), Emission of trace gases and aerosols from biomass burning, Global Biogeochem. Cycles, 15, 955-966.

Arellano, A. F. J., P. S. Kasibhatla, L. Giglio, G. R. Van der Werf, and J. T. Randerson (2004), Top-down estimates of global CO sources using MOPITT measurements, Geophys. Res. Lett., 31, L01104, doi:10.1029/ 2003GL018609.

Berner, U. (1989), Entwicklung und Anwendung empirischer Modelle für die Kohlenstoffisotopenvariation in Mischungen thermogener Erdgase, Dissertation, Univ. of Clausthal, Clausthal-Zellerfeld, Germany.

Boutton, T. W. (1991), Stable carbon isotope ratios of natural materials: II. Atmospheric, terrestrial, marine, and freshwater environments, in Carbon Isotope Techniques, edited by D. Coleman and B. Fry, pp. 173-185, Elsevier, New York.

Faber, E. (1987), Zur Isotopengeochemie gasförmiger Kohlenwasserstoffe, Erdöl Erdgas Kohle, 103(5), 210-218.

Gautrois, M., T. Brauers, R. Koppmann, F. Rohrer, O. Stein, and J. Rudolph (2003), Seasonal variability and trends of volatile organic compounds in the lower polar troposphere, J. Geophys. Res., 108(D13), 4393, doi:10.1029/2002JD002765.

Guenther, A., et al. (1995), A global model of natural volatile organic compound emissions, J. Geophys. Res., 100, 8873-8892.

Hansen, J., G. Russel, D. Rind, P. Stone, A. Lacis, S. Lebedeff, R. Ruedy, and L. Travis (1983), Efficient three-dimensional global models for climate studies: Models I and II, Mon. Weather Rev., 111, 609-662.

Hao, W. M., and M.-H. Liu (1994), Spatial and temporal distribution of tropical biomass burning, Global Biogeochem. Cycles, 8, 495-503.

Horowitz, L. W., et al. (2003), A global simulation of tropospheric ozone and related tracers: Description and evaluation of MOZART, version 2, J. Geophys. Res., 108(D24), 4784, doi:10.1029/2002JD002853.

Kraus, A., F. Rohrer, E. Grobler, and D. Ehhalt (1996), The global tropospheric distribution of $\mathrm{NO}_{\mathrm{x}}$ estimated by a three-dimensional chemical tracer model, J. Geophys. Res., 101, 18,587-18,604.
Lin, S.-J., and R. B. Rood (1996), Multidimensional flux-form semilagrangian transport schemes, Mon. Weather Rev., 124, 2046-2070.

Müller, J.-F. (1992), Geographical distribution and seasonal variation of surface emissions and deposition velocities of atmospheric trace gases, J. Geophys. Res., 97, 3787-3804.

Olivier, J., A. Bouwman, C. Van der Maas, J. Berdowski, C. Veldt, J. Bloos, A. Visschedijk, P. Zandveld, and J. Haverlag (1996), Description of EDGAR version 2.0: A set of global emissions inventories of greenhouse gases and ozone depleting substances for all anthropogenic and most natural sources on a per country basis and on $1^{\circ} \times 1^{\circ}$ grid, RIVM Rep 771060002, TNO-MEP Rep. R96/119, Natl. Inst. of Public Health and the Environ., Bilthoven, Netherlands.

Parrish, D. D., C. J. Hahn, E. J. Williams, R. B. Norton, F. C. Fehsenfeld, H. Singh, J. D. Shetter, B. W. Gandrud, and B. A. Ridley (1992), Indications of photochemical histories of Pacific air masses from measurements of atmospheric trace species at Point Arena, California, J. Geophys. Res., 97, 15,883-15,901.

Pétron, G., C. Granier, B. Khattatov, J.-F. Lamarque, V. Yudin, J.-F. Müller, and J. Gille (2002), Inverse modeling of carbon monoxide surface emissions using Climate Monitoring and Diagnostics Laboratory network observations, J. Geophys. Res., 107(D24), 4761, doi:10.1029/2001JD001305.

Pétron, G., C. Granier, B. Khattatov, V. Yudin, J.-F. Lamarque, L. Emmons, J. Gille, and D. P. Edwards (2004), Monthly CO surface sources inventory based on the 2000-2001 MOPITT satellite data, Geophys. Res. Lett., 31, L21107, doi:10.1029/2004GL020560.

Prather, M., M. McElroy, S. Wofsy, G. Russell, and D. Rind (1987), Chemistry of the global troposphere: Fluorocarbons as tracers of air motion, J. Geophys. Res., 92, 6579-6613.

Rudolph, J. (1995), The tropospheric distribution and budget of ethane, J. Geophys. Res., 100, 11,369-11,381.

Rudolph, J., and E. Czuba (2000), On the use of isotopic composition measurement of volatile organic compounds to determine the "photochemical age" of an air mass, Geophys. Res. Lett., 27, 3865-3868.

Rudolph, J., D. C. Lowe, R. J. Martin, and T. S. Clarkson (1997), A novel method for compound specific determination of $\delta^{13} \mathrm{C}$ in volatile organic compounds at ppt levels in ambient air, Geophys. Res. Lett., 24(6), 659662.

Saito, T., U. Tsunogai, K. Kawamura, T. Nakatsuka, and N. Yoshida (2002), Stable carbon isotopic compositions of light hydrocarbons over the western North Pacific and implication for their photochemical ages, J. Geophys. Res., 107(D4), 4040, doi:10.1029/2000JD000127.

Shindell, D. T., et al. (2006), Multimodel simulations of carbon monoxide: Comparison with observations and projected near-future changes, J. Geophys. Res., 111, D19306, doi:10.1029/2006JD007100.

Spivakovsky, C. M., et al. (2000), Three dimensional climatological distribution of tropospheric $\mathrm{OH}$ : Update and evaluation, J. Geophys. Res., 105, $8931-8980$.

Still, C. J., J. A. Berry, G. J. Collatz, and R. S. DeFries (2003), Global distribution of $\mathrm{C} 3$ and $\mathrm{C} 4$ vegetation: Carbon cycle implications, Global Biogeochem. Cycles, 17(1), 1006, doi:10.1029/2001GB001807.

Thompson, A., J. Rudolph, F. Rohrer, and O. Stein (2003), Concentration and stable carbon isotopic composition of ethane and benzene using a global three-dimensional isotope inclusive chemical tracer model, J. Geophys. Res., 108(D13), 4373, doi:10.1029/2002JD002883.

Tsunogai, U., N. Yoshida, and T. Gamo (1999), Carbon isotopic composition of C2-C5 hydrocarbons and methyl chloride in urban, coastal, and maritime atmospheres over the western North Pacific, J. Geophys. Res., $104,16,033-16,039$.

J. Rudolph and O. Stein, Institut für Chemie und Dynamik der Geosphäre-2: Troposphäre, Forschungszentrum Jülich, D-52425 Jülich, Germany. (o.stein@fz-juelich.de) 